\title{
Partidos na República de 1946: Velhas Teses, Novos Dados*
}

\author{
Jairo Nicolau
}

\begin{abstract}
A bibliografia sobre o sistema partidário da República de 1946 é A extensa. Em levantamento preliminar, encontrei cerca de 130 trabalhos, dentre artigos, livros e teses, sobre o assunto. Temos hoje uma série de proposições sobre as eleições e os partidos do período que se tornaram clássicas. O que faria alguém voltar a escrever sobre este tema?
\end{abstract}

Este trabalho é uma tentativa de superar uma frustração que afetou outros pesquisadores que estudaram a atuação dos partidos no período 1945-64: a impossibilidade de conhecer a votação que cada legenda obteve nas eleições legislativas. A frustração é resultado de um pequeno detalhe: quando os partidos se coligavam para disputar as eleições proporcionais (deputado federal, estadual e vereador), apenas

\footnotetext{
* Agradeço à Vanessa Campagnac e à Marina Vivas pelo inestimável trabalho de coleta e organização dos dados, à Fundação de Amparo à Pesquisa do Estado do Rio de Janeiro - FAPERJ pela dotação de recursos que viabilizaram a pesquisa, a Charles Pessanha as observações precisas e aos dois pareceristas anônimos de Dados e aos meus alunos no Laboratório de Partidos e Eleições pela leitura atenta e comentários oportunos. Gostaria de fazer um agradecimento especial a Wanderley Guilherme dos Santos pelos comentários minuciosos à primeira versão deste trabalho. Este artigo é dedicado a Fernando Limongi que, ao lamentar não poder trabalhar com a votação dos partidos do período 1945-64, acabou me incentivando a realizar esta empreitada.
}

DADOS - Revista de Ciências Sociais, Rio de Janeiro, Vol. 47, n-1, 2004, pp. 85 a 129. 
os votos dados à coligação eram apresentados na estatística eleitoral. Particularmente com relação à Câmara dos Deputados, a análise fica prejudicada por conta da alta proporção que os votos dos partidos coligados representam na votação total ${ }^{1}$. Por isso, os principais estudos sobre o sistema partidário do período (Soares, 1976; Souza, 1976; Lima Junior, 1983; Lavareda, 1991; Santos, 2003) precisaram criar outras estratégias para dimensionar a força dos partidos e a evolução do sistema partidário: trabalhar com o número de cadeiras, ignorar as coligações, considerar a votação das coligações como se fosse um único partido. Tais artifícios têm alguns limites, por exemplo: nunca se soube ao certo como foi a evolução da votação dos partidos nos estados, nem foi possível calcular com precisão uma série de indicadores que dependem da especificação dos votos de cada partido para serem calculados. A dúvida é se a ausência desses dados não pode ter distorcido as análises, apontando tendências (ou deixando de apontá-las) que só poderiam ser assinaladas com precisão mediante os resultados eleitorais.

Este artigo tem dois movimentos. O primeiro é apresentar uma proposta para a organização da estatística eleitoral da República de 1946. A partir da identificação da legenda de um número expressivo de candidatos, foi possível chegar a um resultado muito próximo da votação que cada partido obteve individualmente na disputa para a Câmara dos Deputados. O segundo é testar algumas proposições clássicas da literatura sobre o sistema partidário brasileiro à luz dos dados eleitorais desagregados por partido. A pergunta é se a análise dos novos dados confirma ou traz novos elementos aos estudos sobre o sistema partidário do período.

\section{PROPOSTA PARA UMA NOVA ORGANIZAÇÃO DA ESTATÍSTICA ELEITORAL DA REPÚBLICA DE 1946}

Os resultados das eleições realizadas entre 1945 e 1962 foram publicados em sete volumes pelo Tribunal Superior Eleitoral - TSE. Em linhas gerais, as informações estão bem organizadas, embora existam algumas deficiências: erros de digitação, dados incompletos, discrepância de valores em duas fontes oficiais diferentes e, em alguns casos, até prováveis manipulações ${ }^{2}$. Mas nada que tenha impedido que as tendências gerais do comportamento eleitoral do período tivessem sido capturadas pelos estudiosos. 
Para a Câmara dos Deputados, os dados são apresentados de duas maneiras. A primeira é uma lista com o nome e a votação recebida pelos candidatos; a segunda traz o total de votos obtidos pelos partidos nas diversas unidades da Federação. Nos dois casos, quando havia coligação, a estatística não discriminava a votação de cada partido separadamente. Este pequeno detalhe, que tanta dor de cabeça deu aos pesquisadores, não deriva de um possível descuido dos organizadores da estatística eleitoral, mas das regras da disputa partidária no período.

A legislação da República de 1946 era pouco exigente com relação à filiação partidária. Não havia nenhum documento legal comprovando o vínculo de um cidadão com determinado partido. Para concorrer em uma eleição, o partido (ou coligação) precisava apenas registrar sua lista de candidatos quinze dias antes do pleito $^{3}$. Nas situações em que havia coligação, não havia indicação do partido ao qual cada candidato estava vinculado - nestes casos, a estatística eleitoral trazia apenas a lista dos partidos que disputaram a eleição (em outros, nem isso) e um rol de candidatos inscritos.

Outra informação que não consta das estatísticas é o total de votos de legenda recebidos pelos partidos. Entre 1945 e 1958, não havia cédula oficial nas eleições para a Câmara dos Deputados, e a legislação sugeria que o partido e o nome do candidato constassem da cédula. O voto era computado apenas para a legenda nos casos de imprecisão: se a cédula contivesse nome de um partido e candidato inscrito por outro; se duas cédulas com nomes de dois diferentes candidatos fossem colocadas na sobrecarta ${ }^{4}$. A partir da introdução da cédula oficial, em 1962, o voto de legenda passou a ser uma opção para o eleitor, pois nela havia um espaço no qual era possível escrever as iniciais do partido ou da coligação. A votação final dos partidos que aparece nas estatísticas é o somatório dos votos nominais e os computados para a legenda. Nos casos de partidos coligados, os votos eram contabilizados para a coligação, e não para cada legenda individualmente.

Ao lidar com os dados das eleições para a Câmara dos Deputados do período 1945-64, constatei que, apesar de a estatística oficial não indicar o partido dos candidatos que concorriam por coligações, esta informação podia ser obtida em outras fontes. Percebi que, caso conseguisse identificar o partido de um número significativo de candidatos, talvez chegasse muito próximo da votação alcançada pelos parti$\operatorname{dos}^{5}$. O primeiro passo foi consultar trabalhos (fontes oficiais e perfis 


\section{Jairo Nicolau}

biográficos traçados por pesquisadores) que pudessem indicar o partido dos candidatos. Foram consultados:

- Diários do Congresso Nacional, 1945-1965: traz a lista dos deputados federais em cada sessão legislativa;

- Deputados Brasileiros 1946-1967, David Fleischer: apresenta pequenos perfis dos deputados eleitos;

- Quem Foi Quem na Assembléia Constituinte de 1946, Sérgio Soares Braga: oferece informações minuciosas sobre os deputados que elaboraram a Constituição de 1946;

- Deputados Federais Brasileiros 1826-1976, Câmara dos Deputados: exibe uma lista com o nome e o partido de todos os deputados brasileiros;

- Dicionário Histórico-Biográfico Brasileiro, Alzira Abreu et alii (orgs.): expõe o perfil dos deputados eleitos e o dos suplentes que assumiram o mandato.

As cinco eleições para a Câmara dos Deputados (1945, 1950, 1954, 1958 e 1962) realizadas no período foram disputadas por 5.242 candidatos. Após pesquisa junto às fontes enumeradas, foi possível identificar o partido de 4.624 (88\%) deles. Um dado positivo é que os candidatos identificados estão entre os que receberam as maiores votações, por isso, a taxa de votos destes chegou a $96 \%$ da votação dos candidatos em todo o período (Tabela 1).

Tabela 1

Candidatos e Grau de Identificação

Eleições para a Câmara dos Deputados

(1945-62)

\begin{tabular}{l|c|c|c|c}
\hline Eleições & $\begin{array}{c}\text { No de Candidatos } \\
\text { A }\end{array}$ & $\begin{array}{c}\text { No de Candidatos } \\
\text { cujo Partido Foi } \\
\text { Identificado } \\
\text { B }\end{array}$ & $\begin{array}{c}\text { \% } \\
\text { B/A }\end{array}$ & $\begin{array}{c}\text { \% de Votos dos Candi- } \\
\text { datos cujo Partido Foi } \\
\text { Identificado }\end{array}$ \\
\hline 1945 & 938 & 936 & 99,8 & C \\
1950 & 1.063 & 968 & 91,1 & 99,8 \\
1954 & 1.057 & 946 & 89,5 & 96,3 \\
1958 & 987 & 847 & 85,8 & 96,6 \\
1962 & 1.197 & 927 & 77,4 & 94,2 \\
\hline Total & $\mathbf{5 . 2 4 2}$ & $\mathbf{4 . 6 2 4}$ & $\mathbf{8 8 , 2}$ & $\mathbf{9 6 , 0}$ \\
\hline
\end{tabular}

Fonte: Os dados desta tabela e das seguintes foram elaborados a partir das "Fontes Primárias e Perfis Biográficos" apresentados nas referências bibliográficas. 
O passo seguinte foi fazer o somatório dos votos de todos os candidatos de uma coligação que pertenciam a um determinado partido - os votos dos candidatos não identificados foram desprezados. Tal procedimento permitiu distinguir os votos de cada partido da coligação. Para os partidos que concorreram sozinhos, utilizei o total de votos (nominal e de legenda) obtidos ${ }^{6}$. A Tabela 2 apresenta o resultado dessa operação com a votação absoluta e o percentual de todos os vinte partidos que disputaram as eleições no período ${ }^{7}$.

Tabela 2

Votação (Absoluta e Percentual) por Partido

Câmara dos Deputados (1945-62)

\begin{tabular}{|c|c|c|c|c|c|c|c|c|c|c|}
\hline \multirow[t]{2}{*}{ Partidos } & \multicolumn{2}{|l|}{1945} & \multicolumn{2}{|l|}{1950} & \multicolumn{2}{|l|}{1954} & \multicolumn{2}{|l|}{1958} & \multicolumn{2}{|l|}{1962} \\
\hline & $\mathbf{N}$ & $\%$ & $\mathbf{N}$ & $\%$ & $\mathbf{N}$ & $\%$ & $\mathbf{N}$ & $\%$ & $\mathbf{N}$ & $\%$ \\
\hline PSD & 2.495 .944 & 42,4 & 2.440 .458 & 32,8 & 2.885 .140 & 32,6 & 3.687 .247 & 33,6 & 3.399 .471 & 30,1 \\
\hline UDN & 1.575 .375 & 26,8 & 1.812 .849 & 24,3 & 1.936 .935 & 21,9 & 2.319 .713 & 21,1 & 2.547.207 & 22,6 \\
\hline РTB & 603.500 & 10,2 & 1.374 .468 & 18,5 & 1.654 .727 & 18,7 & 2.250 .764 & 20,5 & 2.796.209 & 24,8 \\
\hline РCB & 511.332 & 8,7 & & & & & & & & \\
\hline PR & 219.562 & 3,7 & 294.609 & 4,0 & 485.180 & 5,5 & 626.470 & 5,7 & 305.910 & 2,7 \\
\hline PDC & 101.636 & 1,7 & 82.483 & 1,1 & 143.062 & 1,6 & 325.991 & 3,0 & 618.478 & 5,5 \\
\hline PRP & 94.447 & 1,6 & 84.662 & 1,1 & 100.350 & 1,1 & 195.532 & 1,8 & 146.262 & 1,3 \\
\hline PRProg. & 70.675 & 1,2 & & & & & & & & \\
\hline PAN & 17.866 & 0,3 & & & & & & & & \\
\hline PPS & 107.321 & 1,8 & & & & & & & & \\
\hline PSP & & & 722.427 & 9,7 & 988.496 & 11,2 & 694.359 & 6,3 & 551.134 & 4,9 \\
\hline PL & 57.341 & 1,0 & 122.862 & 1,7 & 232.709 & 2,6 & 154.127 & 1,4 & 135.314 & 1,2 \\
\hline PRD & 33.647 & 0,6 & & & & & & & & \\
\hline PTN & & & 211.090 & 2,8 & 192.855 & 2,2 & 272.720 & 2,5 & 319.522 & 2,8 \\
\hline PST & & & 163.341 & 2,2 & 32.440 & 0,4 & 115.365 & 1,1 & 191.610 & 1,7 \\
\hline PRT & & & 73.501 & 1,0 & 65.325 & 0,7 & 77.187 & 0,7 & 83.995 & 0,7 \\
\hline PSB & & & 39.854 & 0,5 & 143.398 & 1,6 & 250.132 & 2,3 & 80.577 & 0,7 \\
\hline POT & & & 19.384 & 0,3 & & & & & & \\
\hline PRB & & & 4.151 & 0,1 & & & & & & \\
\hline MTR & & & & & & & & & 113.409 & 1,0 \\
\hline Total & 5.888 .646 & 100,0 & 7.446.139 & 100,0 & 8.860 .617 & 100,0 & 10.969 .607 & 100,0 & 11.289 .098 & 100,0 \\
\hline
\end{tabular}

Fonte: Ver fonte da Tabela 1.

A identificação dos partidos de todos os candidatos eleitos pelas coligações permitiu fazer também um mapeamento completo da distribuição partidária das cadeiras na Câmara dos Deputados. A Tabela 3 apresenta o número absoluto e o percentual de cadeiras obtidas pelos partidos nas cinco eleições realizadas entre 1945 e 1962. Os dados apresentados diferem um pouco dos do $\mathrm{TSE}^{8}$. O que explicaria essas discrepâncias? Uma informação que acompanha os dados oficiais sobre a representação dos partidos diz que eles foram fornecidos pela Câmara Federal. Minha sugestão é que estes últimos se referem ao 
momento da diplomação, ou da posse dos deputados, e não ao das eleições. Nesse sentido, pequenas mudanças pós-eleitorais (tais como a posse de suplentes e a troca de legendas) devem estar refletidas nos números do TSE. Assim, é possível compreender, por exemplo, por que nos resultados de 1954 seis deputados aparecem sob o rótulo de "sem partido", classificação sem sentido caso o resultado eleitoral fosse considerado?

Tabela 3

Número de Cadeiras (Absoluto e Percentual) por Ano e Partido

Câmara dos Deputados (1945-62)

\begin{tabular}{l|cc|cc|cc|cc|cc}
\hline \multirow{2}{*}{ Partidos } & \multicolumn{2}{|c|}{$\mathbf{1 9 4 5}$} & \multicolumn{2}{|c|}{$\mathbf{1 9 5 0}$} & \multicolumn{2}{c|}{$\mathbf{1 9 5 4}$} & \multicolumn{2}{c|}{$\mathbf{1 9 5 8}$} & \multicolumn{2}{c}{1962} \\
\cline { 2 - 12 } & $\mathbf{N}$ & $\mathbf{\%}$ & $\mathbf{N}$ & $\mathbf{\%}$ & $\mathbf{N}$ & $\mathbf{\%}$ & $\mathbf{N}$ & $\mathbf{\%}$ & $\mathbf{N}$ & $\mathbf{\%}$ \\
\hline PSD & 151 & 52,8 & 112 & 36,8 & 119 & 36,5 & 119 & 36,5 & 125 & 30,6 \\
UDN & 81 & 28,3 & 81 & 26,6 & 74 & 22,7 & 70 & 21,5 & 96 & 23,5 \\
PTB & 22 & 7,7 & 51 & 16,8 & 61 & 18,7 & 63 & 19,3 & 105 & 25,7 \\
PCB & 14 & 4,9 & & & & & & & & \\
PR & 9 & 3,1 & 10 & 3,3 & 18 & 5,5 & 17 & 5,2 & 7 & 1,7 \\
PPS & 4 & 1,4 & & & & & & & & \\
PRProg. & 2 & 0,7 & & & & & & & & \\
PSP & & & 24 & 7,9 & 27 & 8,3 & 25 & 7,7 & 21 & 5,1 \\
PDC & 2 & 0,7 & 2 & 0,7 & 2 & 0,6 & 7 & 2,1 & 19 & 4,6 \\
PL & 1 & 0,3 & 6 & 2,0 & 10 & 3,1 & 3 & 0,9 & 5 & 1,2 \\
PST & & & 9 & 3,0 & & & 2 & 0,6 & 7 & 1,7 \\
PTN & & & 5 & 1,6 & 6 & 1,8 & 6 & 1,8 & 11 & 2,7 \\
PSB & & & 1 & 0,3 & 4 & 1,2 & 9 & 2,8 & 4 & 1,0 \\
PRP & & & 2 & 0,7 & 4 & 1,2 & 3 & 0,9 & 3 & 0,7 \\
PRT & & & 1 & 0,3 & 1 & 0,3 & 2 & 0,6 & 3 & 0,7 \\
MTR & & & & & & & & & 3 & 0,7 \\
\hline Total & $\mathbf{2 8 6}$ & $\mathbf{1 0 0 , 0}$ & $\mathbf{3 0 4}$ & $\mathbf{1 0 0} \mathbf{0 0}$ & $\mathbf{3 2 6}$ & $\mathbf{1 0 0 , 0}$ & $\mathbf{3 2 6}$ & $\mathbf{1 0 0 , 0}$ & $\mathbf{4 0 9}$ & $\mathbf{1 0 0 , 0}$ \\
\hline
\end{tabular}

Fonte: Ver fonte da Tabela 1.

\section{VELHAS TESES, NOVOS DADOS}

Depois de identificar a votação que cada partido obteve nas eleições para a Câmara dos Deputados, o passo seguinte foi verificar se esses dados traziam novos elementos para interpretar o sistema partidário da República de 1946. Em primeiro lugar, resolvi reavaliar algumas proposições clássicas apresentadas pelos principais autores que estudaram o período ${ }^{10}:$ a) os partidos conservadores estavam declinando e o PTB crescendo (Gláucio Soares); b) os partidos estavam passando por um processo de nacionalização (Olavo Brasil de Lima Junior); c) 
as eleições para a Câmara dos Deputados conheceram um contínuo processo de fragmentação (Wanderley Guilherme dos Santos). Em seguida, calculei o índice de volatilidade, indicador que tradicionalmente mensura a instabilidade eleitoral, mas que ainda não tinha sido utilizado com resultados das eleições da República de 1946.

A proposição clássica sobre a evolução dos partidos durante o período 1946-64 foi apresentada por Gláucio Soares (1976). O autor reconhece as limitações de uma análise baseada exclusivamente na representação dos partidos:

\footnotetext{
"A análise das modificações na força eleitoral dos partidos políticos deveria basear-se nos votos recebidos nas diversas eleições. Entretanto, a crescente significação das alianças e coligações eleitorais durante o período impede a assignação dos votos aos partidos, uma vez que a informação disponível não discrimina a votação dos partidos que compõem as alianças. Tornou-se, portanto, necessário utilizar o número de eleitos, a despeito das distorções introduzidas pelo sistema eleitoral neste número" (idem:89).
}

Portanto, é com base na representação dos partidos na Câmara dos Deputados que Soares aponta como principais características do quadro partidário no período o declínio do PSD e da UDN e o crescimento do $\mathrm{PTB}^{11}$.

A Tabela 4 apresenta o percentual de votos de cada partido nas eleições para a Câmara dos Deputados. O PTB teve um crescimento expressivo e constante de 14,6 pontos percentuais ao longo do período (passou de 10,2\% em 1945 para 24,8\% em 1962). O avanço mais significativo ocorreu em 1950, quando o partido cresceu 8,3 pontos percentuais - parte deste crescimento, provavelmente, se deveu ao fato de $o$ PCB não participar da disputa, e outra parte aos reflexos da candidatura vitoriosa de Getulio Vargas à Presidência. O partido conquistou outro avanço importante nas eleições de 1962, quando recebeu 4,3 pontos percentuais a mais de votos do que no pleito anterior.

O PSD seguiu caminho contrário, perdendo 12,3 pontos percentuais quando se comparam a primeira e a última eleição do período. O declínio mais acentuado ocorreu em 1950, ocasião em que o partido perdeu 9,6 pontos percentuais. Nas duas eleições seguintes (1954 e 1958), a votação do PSD praticamente não se alterou, mas voltou a declinar (3,5 pontos percentuais) em 1962. Estes dados mostram que a análise 
Tabela 4

Evolução da Votação dos Partidos por Bloco Ideológico

Câmara dos Deputados (1945-62)

(\%)

\begin{tabular}{l|c|c|c|c|c}
\hline Partidos & $\mathbf{1 9 4 5}$ & $\mathbf{1 9 5 0}$ & $\mathbf{1 9 5 4}$ & $\mathbf{1 9 5 8}$ & $\mathbf{1 9 6 2}$ \\
\hline PRP & 1,6 & 1,1 & 1,1 & 1,8 & 1,3 \\
PR & 3,7 & 4,0 & 5,5 & 5,7 & 2,7 \\
UDN & 26,8 & 24,3 & 21,9 & 21,1 & 22,6 \\
\hline Direita & $\mathbf{3 2 , 1}$ & $\mathbf{2 9 , 4}$ & $\mathbf{2 8 , 5}$ & $\mathbf{2 8 , 6}$ & $\mathbf{2 6 , 6}$ \\
\hline PL & 1,0 & 1,7 & 2,6 & 1,4 & 1,2 \\
PDC & 1,7 & 1,1 & 1,6 & 3,0 & 5,5 \\
PSD & 42,4 & 32,8 & 32,6 & 33,6 & 30,1 \\
\hline Centro & $\mathbf{4 5 , 1}$ & 35,5 & 36,8 & 38,0 & 36,8 \\
\hline PTB & 10,2 & 18,5 & 18,7 & 20,5 & 24,8 \\
PCB & 8,7 & & & & \\
PSB & & 0,5 & 1,6 & 2,3 & 0,7 \\
PSP & & 9,7 & 11,2 & 6,3 & 4,9 \\
Pequenos trabalhistas & 3,9 & 6,3 & 3,3 & 4,2 & 6,3 \\
\hline Esquerda & $\mathbf{2 2 , 8}$ & $\mathbf{3 5 , 0}$ & $\mathbf{3 4 , 7}$ & 33,4 & 36,6 \\
\hline Total & $\mathbf{1 0 0 , 0}$ & $\mathbf{1 0 0 , 0}$ & $\mathbf{1 0 0 , 0}$ & $\mathbf{1 0 0 , 0}$ & $\mathbf{1 0 0 , 0}$ \\
\hline
\end{tabular}

Fonte: Ver fonte da Tabela 1.

sobre o PSD feita por Soares (idem), baseada apenas na evolução do número de cadeiras do partido na Câmara dos Deputados, acabou superestimando a intensidade do declínio do mesmo. Particularmente em relação às cadeiras recebidas pelo PSD (ver Tabelas 2 e 3), é válido destacar os efeitos produzidos pela fórmula eleitoral nas eleições de 1945. Nestas eleições, as cadeiras não ocupadas após a primeira distribuição (sobras) foram alocadas para o partido com mais votos no estado. Como o PSD foi o mais votado em 15 das 22 unidades da Federação, ele acabou sendo fortemente sobre-representado - com $42 \%$ dos votos, recebeu 53\% das cadeiras. A fórmula foi alterada em 1950, o que ajuda a explicar por que o declínio do partido em percentual de cadeiras foi muito mais acentuado (16 pontos percentuais) do que em votos ( 9,6 pontos percentuais). Já a UDN perdeu 4,2 pontos percentuais quando se compara a primeira com a última eleição. Mas é interessante observar que o partido obteve um pequeno crescimento nas eleições de 1962 em relação às duas anteriores. 
A análise de apenas três partidos poderia esconder alterações ocorridas nos blocos ideológicos do sistema partidário. Por exemplo: será que houve realmente um declínio do campo conservador, tal como sugerido por Soares (idem)? Por outro lado, será que o campo da esquerda conheceu um crescimento constante no período? Para avaliar as mudanças ideológicas, agreguei os partidos em três blocos: direita (PRP, PR e UDN), centro (PL, PDC e PSD) e esquerda (PTB, PCB, PSB, PSP e pequenos partidos trabalhistas $)^{12}$.

A Tabela 4 apresenta os resultados das eleições para a Câmara dos Deputados por bloco ideológico. As tendências para o centro e a direita são claras: o primeiro perdeu votos em todas as eleições ( 8,3 pontos ao longo do período); a segunda também conheceu uma tendência declinante ( 5,5 pontos ao longo do período). Já a esquerda, embora tenha tido um crescimento de 13,8 pontos percentuais, quando comparadas a primeira e a última eleição, acabou perdendo votos durante a década de 50. É interessante observar que nas eleições de 1962 - geralmente apontada como a eleição crítica do período - as alterações tenham sido tão reduzidas, com oscilações de no máximo 3,2 pontos percentuais por bloco ideológico.

Uma segunda proposição clássica sobre o sistema partidário da República de 1946 foi apresentada por Lima Junior (1983), que chamou a atenção para o processo de nacionalização dos partidos:

“O período 1945-62 caracterizou-se, ainda, pela tendência à expansão geográfica por parte de todos os partidos, com vistas a maximizar o apoio eleitoral. Por um lado, os partidos nacionais se expandiram geograficamente até o ponto em que as condições locais de competição lhes permitia penetrar no eleitorado; por outro, partidos com apoio essencialmente regional cresceram eleitoralmente até o ponto em que lograram disputar, com maior probabilidade de sucesso, eleições federais. Esse processo global, diríamos, de nacionalização da política, resultou, assim, tanto de variações das preferências eleitorais como do esforço organizacional dos partidos." (idem:127)

Um reparo à proposição da nacionalização de Lima Junior foi feito por Wanderley Guilherme dos Santos (2003), que considerou que tal processo teria ocorrido com os três maiores partidos, mas não com os pequenos. A partir da contagem do número de estados que um partido necessita para obter $50 \%$ da representação, o autor chega à seguinte conclusão: 


\begin{abstract}
"À parte os casos extremos do PSB e do PRP, que necessitavam de número crescente de estados para formar porcentagem cada vez menor do total da representação - indicador aparente de nacionalização - os demais se encaminhavam para a estadualização (PSP e PR nitidamente) ou jamais deixaram de ser epidérmicas agremiações estaduais (PST, PL, PTN e PRT).

Na verdade, se se pode falar em nacionalização do sistema partidário, no período, ela se refere sobretudo às três maiores legendas [...]" (idem:151, ênfases no original).
\end{abstract}

Com a votação discriminada por partido, é possível avaliar com maior precisão o desempenho de cada um deles por unidade da Federação. Será que os pequenos realmente estavam ampliando suas bases eleitorais pelo país? Para dimensionar o padrão de concentração dos votos, utilizo o indice de desigualdade regional cumulativa proposto por Derek Urwin (1983:228) em trabalho sobre os partidos regionais na Europa. O índice é calculado para cada partido e sua operacionalização é bastante simples. Em primeiro lugar, calcula-se a diferença entre o percentual da votação nacional de um partido em determinado estado e o percentual que esse estado representa no eleitorado nacional $^{13}$. O resultado de cada estado é somado, desconsiderando-se os sinais positivo e negativo, obtendo-se valores que variam de 0 a 1 . Quanto mais concentrada é a votação de um dado partido, mais ele se aproxima de 1 .

Os dados da Tabela 5 exibem os valores do índice de desigualdade regional cumulativa dos partidos que disputaram as eleições para a Câmara dos Deputados entre 1945 e 1962. Os três maiores partidos (PSD, UDN e PTB) tiveram baixas taxas de voto regionalizado, podendo ser considerados, como apontou Santos (2003:151), partidos nacionalizados. Em relação aos pequenos partidos, os índices mostram que nenhum deles estabeleceu uma tendência clara de nacionalização ${ }^{14}$.

Uma simples observação da votação dos partidos nas diferentes unidades da Federação (ver Anexo 1) mostra como os pequenos partidos concentraram sua votação em um número reduzido de estados. Vejamos, por exemplo, o desempenho dos quatro mais votados (PDC, PSP, PTN e PR) nas eleições de 1962. O PDC foi votado em nove unidades, mas obteve mais de $10 \%$ dos votos em apenas três delas (RN, SP e PR); o PSP disputou em dez unidades, mas obteve votações expressivas em cinco delas (AL, SP, MA, PA e GO); o PTN disputou em quatro, 
Tabela 5

Índice de Desigualdade Regional Cumulativa

Câmara dos Deputados (1945-62)

\begin{tabular}{l|c|c|c|c|c}
\hline Partidos & $\mathbf{1 9 4 5}$ & $\mathbf{1 9 5 0}$ & $\mathbf{1 9 5 4}$ & $\mathbf{1 9 5 8}$ & $\mathbf{1 9 6 2}$ \\
\hline PSD & 0,11 & 0,16 & 0,14 & 0,17 & 0,19 \\
UDN & 0,16 & 0,20 & 0,24 & 0,26 & 0,26 \\
PTB & 0,33 & 0,28 & 0,22 & 0,30 & 0,28 \\
PCB & 0,31 & & & & \\
PR & 0,71 & 0,48 & 0,47 & 0,62 & 0,61 \\
PPS & 0,57 & & & & \\
PDC & 0,58 & 0,69 & 0,49 & 0,57 & 0,51 \\
PRP & 0,39 & 0,71 & 0,83 & 0,63 & 0,65 \\
PRProg. & 0,67 & & & & \\
PL & 0,86 & 0,83 & 0,71 & 0,79 & 0,89 \\
PRD & 0,66 & & & & \\
PAN & 0,46 & & & & \\
PSP & & 0,50 & 0,38 & 0,52 & 0,64 \\
PTN & & 0,61 & 0,80 & 0,80 & 0,73 \\
PST & & 0,74 & 0,79 & 0,73 & 0,62 \\
PRT & & 0,66 & 0,78 & 0,76 & 0,82 \\
PSB & & 0,73 & 0,56 & 0,62 & 0,67 \\
POT & & 0,89 & & & \\
PRB & & 0,87 & & & \\
MTR & & & & & 0,69 \\
\hline
\end{tabular}

Fonte: Ver fonte da Tabela 1.

mas conseguiu votações relevantes em apenas duas (ES e SP); o PR concorreu em apenas quatro e recebeu votações expressivas em duas delas (SE e MG).

Portanto, a proposição sobre a nacionalização eleitoral dos partidos não encontra amparo nos dados apresentados na Tabela 5: os grandes partidos (PSD, PTB e UDN) conseguiram distribuir sua votação de maneira mais equilibrada pelo território nacional, enquanto os demais acabaram concentrando seus votos em um número restrito de estados.

Uma terceira proposição importante foi apresentada por Wanderley Guilherme dos Santos (2003), que constatou um crescimento da fragmentação partidária na Câmara dos Deputados. O autor trata do tema nas duas partes do livro O Cálculo do Conflito e utiliza três diferentes indicadores para mensurar a concentração/dispersão da distribuição de cadeiras na Câmara dos Deputados: número efetivo de par- 


\title{
Jairo Nicolau
}

tidos (que em algumas passagens - pp. 77 e 82 - aparece sob o título de efetivo número de partidos); a fracionalização; e a fragmentação ${ }^{15}$. A partir do cálculo destes dois últimos, Santos assinala o crescimento da fragmentação parlamentar como uma tendência do período ${ }^{16}$. Abaixo, algumas passagens selecionadas do livro mostram como o autor tratou do tema da fragmentação:

\begin{abstract}
“A tendência à fragmentação crescente entre 1946 e 1964 é claramente confirmada pelos dados. Embora o número de partidos com representação no Congresso permanecesse razoavelmente estável durante o período, variando de dez, em 1946, a treze, em 1962, o índice de fracionalização nominal cresceu de 0,640 no início do período, para 0,780 em 1962" (idem:244).
\end{abstract}

"No capítulo IX apresentei evidências históricas e parlamentares demonstrando que, de 1946 a 1962 (o último ano eleitoral antes de 1964), prevaleceu um padrão de crescente fragmentação na distribuição de cadeiras entre os vários partidos na Câmara dos Deputados. Mais importante, pelo menos na legislatura iniciada em 1963, é que essa fragmentação não correspondeu ao progressivo afrouxamento da filiação dentro do sistema partidário" (idem:334).

"De acordo com o padrão de variação no período, bem como pela comparação entre vários países, conclui-se que o grau de fragmentação no Brasil aumentou consistentemente de 1946 a 1962, colocando o país entre os primeiros lugares em termos de dispersão política, relativamente a outros sistemas políticos para os quais há dados disponíveis" (idem:246).

Para calcular a dispersão das preferências eleitorais, os autores que estudaram o período optaram por duas estratégias diferentes. Lima Junior (1983) e Lavareda (1991) consideraram a votação das coligações como se estas fossem de um único partido, procedimento que subestimou a fragmentação realmente existente. Já Santos (2003) só levou em conta os votos dos partidos, desconsiderando aqueles dados às coligações, estratégia que distorceu os resultados nos estados em que grandes partidos se apresentaram coligados.

Uma das vantagens de ter os votos desagregados por partido é poder calcular com precisão o grau de dispersão das preferências eleitorais. A Tabela 6 apresenta a fragmentação eleitoral por unidade da Federação, medida pelo número efetivo de partidos ${ }^{17}$. Dois dados chamam a atenção. O primeiro é a estabilidade dos valores da fragmentação da 
Câmara dos Deputados entre 1950 e 1962, uma média de 4,8 partidos efetivos. O segundo refere-se à baixa fragmentação no âmbito estadual. A única exceção é São Paulo, que teve um padrão de dispersão superior ao existente na disputa nacional. Portanto, pelo menos no que diz respeito ao plano eleitoral, não há nenhuma evidência de crescimento da fragmentação partidária. Por isso, nenhuma crise do sistema partidário pode ser atribuída a um possível aumento da fragmentação partidária, simplesmente porque ela não ocorreu.

Em geral, a fragmentação partidária no Parlamento tende a ser menor do que a eleitoral, devido aos efeitos mecânicos produzidos pelo sistema eleitoral. Todavia, por causa da regra das coligações em vigor no Brasil, a dispersão parlamentar pode, em certas circunstâncias, ser mais acentuada do que a eleitoral. A dúvida é se tal fenômeno ocorreu durante a República de 1946. A Tabela 7 apresenta o número efetivo de partidos na Câmara dos Deputados. Os dados agregados sugerem uma estabilidade impressionante: uma média de 4,5 partidos efetivos

Tabela 6

Número Efetivo de Partidos

Votos nas Eleições para a Câmara dos Deputados (1945-62)

\begin{tabular}{l|c|c|c|c|c}
\hline Estados & $\mathbf{1 9 4 5}$ & $\mathbf{1 9 5 0}$ & $\mathbf{1 9 5 4}$ & $\mathbf{1 9 5 8}$ & $\mathbf{1 9 6 2}$ \\
\hline Território do Guaporé/Rondônia & & 2,0 & 2,0 & 2,0 & 2,6 \\
Acre & 1,7 & 2,1 & 2,0 & 2,5 & 2,0 \\
Amazonas & 3,4 & 4,0 & 2,7 & 3,4 & 3,0 \\
Território do Rio Branco/Roraima & & 2,1 & 2,2 & 1,9 & 2,3 \\
Pará & 2,5 & 2,7 & 3,4 & 3,0 & 3,3 \\
Amapá & & 1,3 & 1,3 & 2,0 & 2,2 \\
\hline NORTE & $\mathbf{2 , 7}$ & 3,0 & 3,8 & 3,7 & 3,7 \\
Maranhão & 1,8 & 2,7 & 1,8 & 2,1 & 1,8 \\
Piauí & 2,2 & 2,0 & 2,8 & 3,4 & 3,4 \\
Ceará & 3,1 & 2,5 & 3,6 & 3,3 & 3,3 \\
Rio Grande do Norte & 2,9 & 3,2 & 3,0 & 2,0 & 2,9 \\
Paraíba & 2,3 & 2,8 & 3,1 & 2,7 & 3,0 \\
Pernambuco & 3,8 & 3,2 & 3,6 & 2,8 & 3,6 \\
Alagoas & 2,8 & 2,9 & 2,7 & 4,5 & 3,1 \\
Sergipe & 2,4 & 4,2 & 3,2 & 2,7 & 2,9 \\
Bahia & 3,0 & 3,2 & 5,0 & 3,6 & 3,7 \\
\hline NORDESTE & 3,1 & 3,7 & 4,0 & 3,5 & 3,7 \\
\hline
\end{tabular}


Tabela 6

Número Efetivo de Partidos

Votos nas Eleições para a Câmara dos Deputados (1945-62)

\begin{tabular}{l|c|c|c|c|c}
\hline Estados & $\mathbf{1 9 4 5}$ & $\mathbf{1 9 5 0}$ & $\mathbf{1 9 5 4}$ & $\mathbf{1 9 5 8}$ & $\mathbf{1 9 6 2}$ \\
\hline Espírito Santo & 2,2 & 3,3 & 3,5 & 3,0 & 4,7 \\
Minas Gerais & 3,3 & 3,7 & 3,3 & 3,3 & 2,9 \\
Rio de Janeiro & 3,1 & 3,7 & 3,9 & 3,6 & 4,0 \\
São Paulo & 5,0 & 5,3 & 5,7 & 7,8 & 8,2 \\
Distrito Federal & 4,3 & 4,5 & 4,4 & 3,6 & 2,7 \\
\hline SUDESTE & $\mathbf{4 , 2}$ & $\mathbf{5 , 4}$ & $\mathbf{5 , 2}$ & $\mathbf{5 , 7}$ & $\mathbf{5 , 8}$ \\
\hline Paraná & 3,3 & 3,3 & 4,4 & 3,7 & 3,6 \\
Rio Grande do Sul & 2,2 & 3,3 & 3,5 & 2,8 & 3,2 \\
Santa Catarina & 2,4 & 2,6 & 2,9 & 2,5 & 2,6 \\
\hline SUL & $\mathbf{2 , 5}$ & $\mathbf{3 , 5}$ & $\mathbf{4 , 4}$ & $\mathbf{3 , 5}$ & $\mathbf{3 , 7}$ \\
\hline Goiás & 2,3 & 2,8 & 3,0 & 2,5 & 2,7 \\
Mato Grosso & 2,3 & 2,9 & 2,8 & 2,5 & 2,6 \\
\hline CENTRO-OESTE & $\mathbf{2 , 3}$ & $\mathbf{2 , 9}$ & $\mathbf{3 , 0}$ & $\mathbf{2 , 8}$ & $\mathbf{3 , 1}$ \\
\hline Total & $\mathbf{3 , 7}$ & $\mathbf{4 , 7}$ & $\mathbf{4 , 9}$ & $\mathbf{4 , 8}$ & $\mathbf{4 , 7}$ \\
\hline
\end{tabular}

Fonte: Ver fonte da Tabela 1.

nas quatro eleições, a partir de 1950. Mesmo o pleito de 1962, apontado como crítico, conheceu um padrão semelhante ao de 1958.

Se compararmos a votação agregada dos partidos no plano nacional, observaremos que a fragmentação parlamentar foi levemente inferior à da disputa eleitoral nos cinco pleitos (comparar Tabelas 6 e 7). São Paulo aparece novamente como o único caso de alta fragmentação, sobretudo a partir de 1954. As conclusões convergem para as apontadas na fragmentação eleitoral: não há nenhuma evidência de que a dispersão parlamentar tenha aumentado no período. É interessante salientar que, apesar de mostrar dados semelhantes que evidenciavam estabilidade na dispersão de poder parlamentar, Santos $(2003: 77,99)$ chegou a conclusões diferentes.

Um tema praticamente inexplorado pela literatura sobre o sistema partidário do período 1946-64 refere-se à estabilidade das preferências dos eleitores entre duas eleições sucessivas. Lavareda (1991:76-78) compara o percentual de cadeiras de cada partido no pleito de 1962 para a Câmara dos Deputados com o percentual médio das quatro eleições anteriores. De acordo com o padrão de evolução, os partidos 
Tabela 7

Número Efetivo de Partidos

Cadeiras nas Eleições para a Câmara dos Deputados (1945-62)

\begin{tabular}{|c|c|c|c|c|c|}
\hline Estados & 1945 & 1950 & 1954 & 1958 & 1962 \\
\hline Território do Guaporé/Rondônia & & 1,0 & 1,0 & 1,0 & 1,0 \\
\hline Acre & 1,0 & 2,0 & 2,0 & 2,0 & 2,0 \\
\hline Amazonas & 2,3 & 3,3 & 2,0 & 4,5 & 2,9 \\
\hline Território do Rio Branco/Roraima & & 1,0 & 1,0 & 1,0 & 1,0 \\
\hline Pará & 2,0 & 2,5 & 1,8 & 2,8 & 3,6 \\
\hline Amapá & & 1,0 & 1,0 & 1,0 & 1,0 \\
\hline NORTE & 1,9 & 3,2 & 2,5 & 3,8 & 3,3 \\
\hline Maranhão & 2,0 & 2,6 & 1,5 & 2,2 & 1,9 \\
\hline Piauí & 2,0 & 2,0 & 3,3 & 3,8 & 2,9 \\
\hline Ceará & 2,2 & 2,2 & 3,8 & 4,0 & 3,5 \\
\hline Rio Grande do Norte & 2,3 & 2,6 & 2,9 & 2,0 & 2,9 \\
\hline Paraíba & 1,7 & 2,8 & 2,8 & 2,7 & 2,6 \\
\hline Pernambuco & 2,8 & 2,9 & 2,8 & 3,1 & 3,6 \\
\hline Alagoas & 1,8 & 2,8 & 2,6 & 4,8 & 2,6 \\
\hline Sergipe & 2,8 & 4,5 & 3,3 & 2,3 & 2,9 \\
\hline Bahia & 2,5 & 3,2 & 5,0 & 3,5 & 3,6 \\
\hline NORDESTE & 2,6 & 3,6 & 4,0 & 3,7 & 3,6 \\
\hline Espírito Santo & 1,3 & 3,0 & 2,3 & 3,3 & 4,6 \\
\hline Minas Gerais & 2,5 & 2,6 & 3,2 & 3,2 & 3,1 \\
\hline Rio de Janeiro & 2,4 & 3,2 & 3,0 & 3,7 & 4,1 \\
\hline São Paulo & 2,8 & 4,4 & 5,4 & 7,0 & 8,2 \\
\hline Distrito Federal & 3,4 & 3,2 & 4,1 & 3,7 & 3,1 \\
\hline SUDESTE & 3,2 & 4,4 & 4,7 & 5,4 & 5,9 \\
\hline Paraná & 2,0 & 3,5 & 4,3 & 3,5 & 3,5 \\
\hline Rio Grande do Sul & 1,6 & 2,8 & 3,1 & 2,3 & 3,2 \\
\hline Santa Catarina & 1,5 & 2,5 & 2,0 & 2,4 & 2,6 \\
\hline SUL & 1,7 & 3,4 & 4,0 & 3,1 & 3,8 \\
\hline Goiás & 1,7 & 2,3 & 2,7 & 2,3 & 2,8 \\
\hline Mato Grosso & 1,9 & 2,6 & 2,3 & 2,6 & 2,5 \\
\hline CENTRO-OESTE & 1,8 & 2,6 & 2,9 & 2,6 & 3,0 \\
\hline Total & 2,7 & 4,1 & 4,3 & 4,4 & 4,5 \\
\hline
\end{tabular}

Fonte: Ver fonte da Tabela 1. 
foram classificados em seis grupos: declínio acentuado, declínio, estabilidade, crescimento, crescimento acentuado e despontando. $\mathrm{O}$ problema da medida proposta por Lavareda (idem) é que as médias das quatro eleições podem encobrir tendências de longo prazo. Assim, um partido que obteve em cinco disputas, respectivamente, $35 \%, 25 \%, 15 \%, 5 \%, 20 \%$ é um exemplo claro de um partido que estava em declínio, mas teve um crescimento surpreendente na última eleição. Contudo, pela medida proposta por Lavareda (idem) esse partido seria considerado estável: $20 \%$ (média das quatro eleições) $=20 \%$ (votos da última eleição).

Uma medida tradicionalmente empregada para dimensionar as mudanças de preferências entre duas eleições é o índice de volatilidade ${ }^{18}$. (Cabe mencionar que os principais autores que estudaram o período 1946-64 não o utilizaram ${ }^{19}$.) A desagregação dos votos por partido permitiu que o índice fosse calculado para os resultados eleitorais. As mudanças mais intensas ocorreram entre 1945 e 1950 (25,7), e uma série de fatores contribuiu para isso: a cassação do PCB, que não disputou as eleições de 1950; o surgimento de dois novos partidos (PSP e PSB); o declínio da votação do PSD; e o crescimento da votação do PTB. As eleições da década de 50 exibiram pequenas alterações na votação dos partidos, fato que está refletido nas reduzidas taxas de volatilidade: 5,8 (1950-54) e 6,8 (1954-58). A taxa voltou a subir no período 1958-62 $(10,2)$. Para tal, contribuíram o crescimento do PTB e do PDC e o declínio do PSD e PR. É interessante observar que, embora as eleições de 1962 tenham produzido uma maior instabilidade nas preferências eleitorais, o crescimento da taxa de volatilidade foi de apenas 3,4 pontos percentuais (ver Tabela 8).

\section{CONSIDERAÇÕES FINAIS}

Afinal, que quadro partidário emerge da análise empreendida aqui? Em primeiro lugar, cabe destacar as alterações ocorridas entre 1945 e 1950 para a Câmara dos Deputados. Alguns autores (Sartori, 1976; Bartoline e Mair, 1990) chamaram a atenção para a singularidade da eleição fundadora de uma democracia. No caso específico das eleições de 1945, a força do PSD, partido que, utilizando a estrutura das interventorias estaduais do Estado Novo, conseguiu se organizar em todo o território nacional. Os outros partidos ainda contavam com estruturas tênues para a disputa em um número significativo de estados. A fórmula utilizada para distribuir as cadeiras naquele pleito fa- 
Tabela 8

Volatilidade Eleitoral Total

Votação para a Câmara dos Deputados (1945-62)

\begin{tabular}{|c|c|c|c|c|}
\hline Estados & 1945-50 & 1950-54 & 1954-58 & 1958-62 \\
\hline Território do Guaporé/Rondônia & 50,0 & 4,6 & 7,0 & 30,2 \\
\hline Acre & 41,1 & 3,7 & 12,9 & 12,9 \\
\hline Amazonas & 24,1 & 50,4 & 20,4 & 39,3 \\
\hline Território do Rio Branco/Roraima & 50,0 & 96,8 & 30,8 & 87,6 \\
\hline Pará & 23,1 & 25,3 & 21,9 & 12,8 \\
\hline Amapá & 50,0 & 1,4 & 29,9 & 62,0 \\
\hline NORTE & 22,4 & 29,5 & 18,5 & 15,5 \\
\hline Maranhão & 79,6 & 76,1 & 15,0 & 7,0 \\
\hline Piauí & 5,0 & 18,9 & 13,5 & 21,2 \\
\hline Ceará & 23,5 & 21,2 & 14,0 & 20,9 \\
\hline Rio Grande do Norte & 44,5 & 19,5 & 26,7 & 25,0 \\
\hline Paraíba & 22,4 & 10,2 & 32,3 & 29,7 \\
\hline Pernambuco & 28,5 & 19,4 & 23,8 & 41,0 \\
\hline Alagoas & 43,1 & 47,2 & 30,1 & 19,4 \\
\hline Sergipe & 44,5 & 18,0 & 13,4 & 4,3 \\
\hline Bahia & 22,5 & 26,0 & 20,7 & 21,9 \\
\hline NORDESTE & 23,5 & 12,2 & 8,1 & 16,7 \\
\hline Espírito Santo & 26,7 & 18,4 & 14,0 & 26,2 \\
\hline Minas Gerais & 19,2 & 9,9 & 9,2 & 15,0 \\
\hline Rio de Janeiro & 28,9 & 12,6 & 10,5 & 20,1 \\
\hline São Paulo & 46,4 & 14,1 & 21,7 & 17,9 \\
\hline Distrito Federal & 46,4 & 21,5 & 17,0 & 29,6 \\
\hline SUDESTE & 30,2 & 7,2 & 8,1 & 11,8 \\
\hline Paraná & 19,9 & 15,0 & 35,3 & 16,2 \\
\hline Rio Grande do Sul & 42,5 & 8,0 & 11,7 & 8,6 \\
\hline$\underline{\text { Santa Catarina }}$ & 15,1 & 13,7 & 13,2 & 2,1 \\
\hline$\underline{\text { SUL }}$ & 28,3 & 9,9 & 12,0 & 8,5 \\
\hline Goiás & 21,1 & 11,3 & 22,0 & 6,1 \\
\hline Mato Grosso & 21,5 & 16,1 & 9,2 & 3,4 \\
\hline CENTRO-OESTE & 21,3 & 13,0 & 17,8 & 5,1 \\
\hline Total & 25,7 & 5,8 & 6,8 & 10,2 \\
\hline
\end{tabular}

Fonte: Ver fonte da Tabela 1. 
vorecia demasiadamente o partido mais votado em cada estado. Sobretudo por isso, o PSD, com $42,4 \%$ dos votos, conseguiu obter maioria absoluta das cadeiras (52,8\%). O quadro da disputa em 1945 é de baixa fragmentação: $\mathrm{N}=3,7$ (votos) e $\mathrm{N}=2,7$ (cadeiras).

Uma série de mudanças ocorreu entre as eleições de 1945 e 1950. No quadro partidário, o PCB teve seu registro cassado em 1947, e dois novos partidos foram fundados (PSP e PSB). O Código Eleitoral de 1950 alterou as regras de distribuição das cadeiras, adotando uma fórmula que não favorecia tão intensamente o partido mais votado em cada circunscrição eleitoral. As altas taxas de volatilidade eleitoral $(25,7)$ e parlamentar $(31,1)$ refletiram essas mudanças ${ }^{20}$. A disputa de 1950 também conheceu um aumento da fragmentação partidária: o número efetivo de partidos passou de 3,7 para 4,7. Podemos dizer que a década de 50 foi marcada por uma alta estabilidade do sistema partidário e que, apesar das pequenas oscilações na votação dos partidos, o quadro geral de fragmentação manteve-se inalterado. A taxa de volatilidade eleitoral também ficou em patamares reduzidos no período: 5,8 (1954-50) e 6,8 (1958-54).

O padrão de estabilidade do quadro partidário foi relativamente alterado no pleito de 1962, em decorrência, sobretudo, do crescimento do PTB - que passou a ser o segundo partido mais votado e a ter a segunda maior bancada, superando a UDN. Tanto a volatilidade eleitoral $(10,2)$ como a parlamentar $(13,9)$ aumentaram. Apesar disso, a fragmentação não sofreu alterações, o que é explicado, em larga medida, pela estabilidade da votação dos três maiores partidos. O somatório dos votos do PSD, UDN e PTB, ao longo do período, foi o seguinte: $1945(79,4 \%), 1950$ (75,6\%), $1954(73,1 \%), 1958(75,3 \%)$ e $1962(77,4 \%)$. Como se observa, embora tenha havido alterações na votação dos menores partidos, estas tiveram, no agregado, pouca influência sobre a natureza da competição partidária.

Em resumo, os números revelam um quadro de surpreendente estabilidade do sistema partidário, pelo menos na disputa para a Câmara dos Deputados. A pergunta inevitável do leitor é: ora, se não havia evidência de crise grave no sistema partidário, por que ele entrou em colapso em 1964? Respondê-la foge às ambições deste artigo, mas o que nossos dados permitem dizer é que a resposta não será encontrada no âmbito eleitoral. Dito de outra maneira: 1962 não explica 1964.

(Recebido para publicação em dezembro de 2003) (Versão definitiva em abril de 2004) 


\section{NOTAS}

1. O total de votos recebidos pelos partidos coligados sobre o total de votos recebidos pelos partidos nas eleições para a Câmara dos Deputados foi o seguinte: 1950 (20\%), 1954 (27\%), 1958 (36\%) e 1962 (48\%) (ver Souza, 1976).

2. Um exemplo de provável manipulação é encontrado na votação dos candidatos à Câmara dos Deputados dos territórios do Guaporé/Rondônia e Rio Branco/Roraima. Em quatro eleições (1950, 1954, 1958 e 1962), apenas dois candidatos são listados. Ambos receberam sempre um número idêntico de votos.

3. Ver artigo 40 da Lei 7.586 de 1945 e artigo 48 do Código Eleitoral de 1950.

4. Até 1958, nas eleições proporcionais, o processo de votação consistia em inserir a cédula distribuída pelos partidos e candidatos em um envelope (sobrecarta) recebido da mesa eleitoral.

5. Somente depois de ter realizado este trabalho, constatei que Gláucio Soares (2001:138) sugeriu procedimento semelhante: identificar os partidos dos candidatos com o intuito de desagregar os votos dos partidos.

6. Os votos totais computados (votos dos partidos que concorreram sozinhos mais os votos dos candidatos das coligações que foram identificados) em termos percentuais por ano são os seguintes: 1945 (99,9\%), 1950 (98,7\%), $1954(95,9 \%), 1958(95,2 \%)$ e 1962 (93\%). Na primeira versão deste texto, apresentada no XXVII Encontro Anual da Associação Nacional de Pós-Graduação e Pesquisa em Ciências Sociais ANPOCS, projetei os dados não identificados na mesma proporção dos identificados. O resultado é praticamente idêntico ao apresentado aqui.

7. Para observar com mais detalhes a evolução de cada partido, ver o Anexo 1, que traz o percentual de votos de cada legenda por unidade da Federação.

8. Os dados do TSE para as bancadas foram reproduzidos em Hippólito (1985:276-285).

9. O número de deputados eleitos que assumiram os mandatos por partidos diferentes dos que participaram da coligação eleitoral é o seguinte: 5 (1954) e 2 (1962). Estes números não consideram os casos dos suplentes que assumiram uma cadeira por um partido diferente daquele pelo qual disputaram a eleição.

10. Acabei deixando de lado o trabalho de Maria do Carmo Campello de Souza, que, apesar de fundamental, não é tão baseado em evidências quantitativas quanto os demais.

11. Lima Junior (1983) e Lavareda (1991) fizeram reparos à avaliação de Soares, mostrando diferentes padrões de evolução dos partidos nos estados (Lima Junior) e nas disputas para outros cargos (Lavareda). Todavia, não chegaram a questionar as proposições do autor para as eleições da Câmara dos Deputados.

12. Outra classificação dos partidos foi apresentada por Santos (2003:156): partidos de inclinação conservadora (PSD, UDN, PR, PL, PDC e PRP); partidos de inclinação progressista (PTB, PSP, PSB, PST, PTN, PRT e MTR). Para adequá-la à apresentada aqui, basta somar os votos do centro com os da direita.

13. Fiz uma pequena adaptação para o cálculo: no lugar do eleitorado, considerei o total de votos dados aos partidos em cada estado. 


\section{Jairo Nicolau}

14. No estudo sobre os partidos europeus, Derek Urwin (1983) considerou regionalizados os partidos com um índice acima de 0,33 .

15. A fragmentação é o resultado da divisão da fracionalização real sobre a fracionalização máxima possível - situação hipotética na qual os partidos que disputaram a eleição recebem o mesmo percentual de votos ou de cadeiras (ver Santos, 2003:100).

16. Na primeira parte do livro, apesar dos diversos cálculos, Santos (2003) não faz comentários sobre as tendências da fragmentação no plano nacional. Para os estados, o autor afirma que os índices de fragmentação (F como proporção do F máximo) oscilam (idem:149-150). Na segunda, os comentários sobre a fragmentação são muitos, especialmente nas pp. 243-248. As evidências são apresentadas pelo índice F e por F como proporção máxima possível (idem:245).

17. O número efetivo de partidos, proposto por Markku Lakso e Rein Taagepera, mensura o peso relativo de cada partido nas eleições ou no Legislativo. Para maiores detalhes sobre o cálculo, ver Nicolau (1997).

18. O indice de volatilidade ao qual faço referência neste trabalho foi proposto por Mogens Pedersen. A volatilidade total, como também é conhecido este índice, é calculada da seguinte maneira: a) para cada partido que concorreu em uma eleição, diminui-se o percentual de votos (ou cadeiras) que ele obteve na eleição antecedente; b) os valores resultantes da operação(a) para cada partido são somados, desconsiderando-se o sinal; c) o resultado é dividido por dois. Quanto maior for a diferença entre duas eleições consecutivas, maior é a volatilidade. Para maiores detalhes, ver Nicolau (1997).

19. Marcus Figueiredo (1995), em trabalho que analisa os resultados eleitorais do período 1950-78, utiliza o índice de volatilidade. O autor calcula o índice para as mudanças no plano parlamentar, mas os resultados apresentados (idem:126) são muito diferentes dos calculados neste trabalho e referidos no Anexo 3.

20. Os dados sobre a volatilidade parlamentar são apresentados no Anexo 3.

\section{REFERÊNCIAS BIBLIOGRÁFICAS}

BARTOLINE, Stefano e MAIR, Peter. (1990), Identity, Competition, and Electoral Availability: The Stabilization of European Electorates, 1885-1985. Cambridge, Cambridge University Press.

FIGUEIREDO, Marcus. (1995), “Volatilidade Eleitoral em Eleições Parlamentares: 1950-1980". Opinião Pública, vol. III, no 3.

HIPPÓLITO, Lucia. (1985), De Raposas e Reformistas: O PSD e a Experiência Democrática Brasileira (1945-1964). Rio de Janeiro, Paz e Terra.

LAVAREDA, Antônio. (1991), A Democracia nas Urnas: O Processo Partidário Eleitoral Brasileiro. Rio de Janeiro, Rio Fundo/IuperJ.

\section{4}


LIMA JUNIOR, Olavo Brasil de. (1983), Os Partidos Políticos Brasileiros - A Experiência Federal e Regional: 1945/64. Rio de Janeiro, Graal.

NICOLAU, Jairo. (1997), “Notas sobre os Quatro Índices mais Utilizados nos Estudos Eleitorais", in O. B. de Lima Junior (org.), O Sistema Partidário Brasileiro. Rio de Janeiro, Fundação Getulio Vargas Editora, pp. 313-320.

SANTOS, Wanderley Guilherme dos. (2003), O Cálculo do Conflito: Estabilidade e Crise na Política Brasileira. Belo Horizonte/Rio de Janeiro, UFMG/IUPERJ.

SARTORI, Giovanni. (1976), Parties and Party Systems: A Framework for Analysis. Cambridge, Cambridge University Press.

SOARES, Gláucio Ary Dillon. (1976), Sociedade e Política no Brasil. São Paulo, Difusão Européia do Livro.

. (2001), A Democracia Interrompida. Rio de Janeiro, Fundação Getulio Vargas Editora.

SOUZA, Maria do Carmo Campello de. (1976), Estado e Partidos Políticos no Brasil (1939 a 1964). São Paulo, Alfa-Ômega.

URWIN, Derek W. (1983), “Harbinger, Fossil or Fleabite? 'Regionalism' and the West European Party Mosaic", in H. Daalder e P. Mair (eds.), Western European Party Systems: Continuity and Change. London, Sage.

\section{Fontes Primárias e Perfis Biográficos}

Quem Foi Quem na Assembléia Constituinte de 1946. Um Perfil Socioeconômico da Constituinte de 1946. Sérgio Soares Braga. Brasília, Coordenação de Publicações/Câmara dos Deputados, 1998.

Deputados Brasileiros 1946-1967. David Fleischer. Brasília, Câmara dos Deputados, 1981.

Deputados Federais Brasileiros 1826-1976. Brasília, Centro de Documentação e Informação/Câmara dos Deputados, 1976.

Diários do Congresso Nacional, 1945-1965.

Dicionário Histórico-Biográfico Brasileiro. Alzira Abreu, Israel Beloch, Fernando Lattman-Weltman, Sérgio Lamarão (orgs.). Rio de Janeiro, Fundação Getulio Vargas Editora.

Dados Estatísticos: Eleições Federais, Estaduais e Municipais (vols. 1-7). Rio de Janeiro, Tribunal Superior Eleitoral, Departamento de Imprensa Nacional. 
Jairo Nicolau

\section{GLOSSÁRIO}

MTR - Movimento Trabalhista Renovador

PAN - Partido dos Aposentados da Nação

PCB - Partido Comunista Brasileiro

PDC - Partido Democrata Cristão

PL - Partido Liberal

POT - Partido Orientador Trabalhista

PPS - Partido Popular Sindicalista

PR - Partido Republicano

PRB - Partido Ruralista Brasileiro

PRD - Partido Republicano Democrático

PRP - Partido da Representação Popular

PRProg - Partido Republicano Progressista

PRT - Partido Reformador Trabalhista

PSB - Partido Socialista Brasileiro

PSD - Partido Social Democrático

PSP - Partido Social Progressista

PST - Partido Social Trabalhista

PTB - Partido Trabalhista Brasileiro

PTN - Partido Trabalhista Nacional

UDN - União Democrática Nacional 


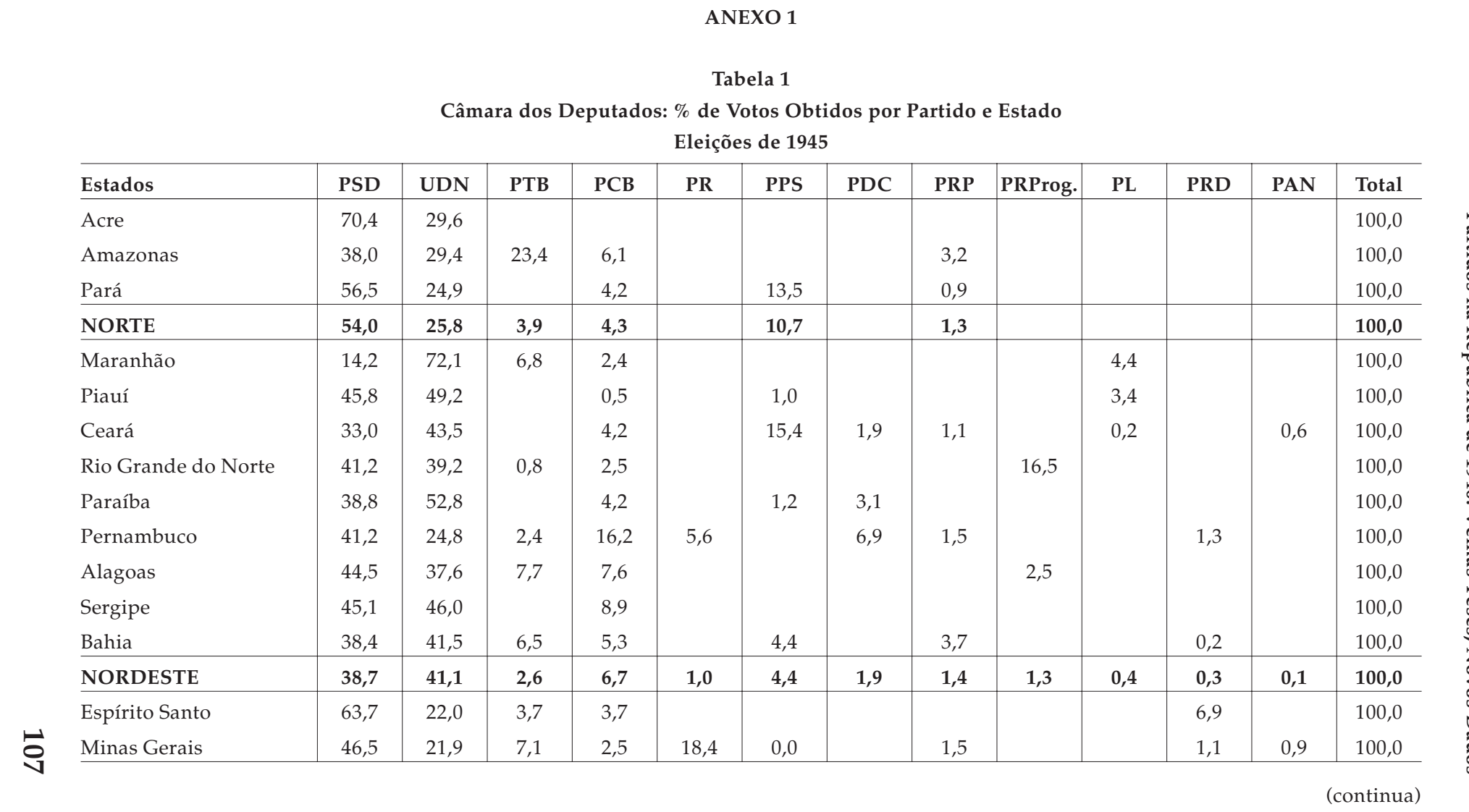


Tabela 1

Câmara dos Deputados: \% de Votos Obtidos por Partido e Estado

Eleições de 1945

(continuação)

\begin{tabular}{|c|c|c|c|c|c|c|c|c|c|c|c|c|c|}
\hline Estados & PSD & UDN & РТВ & РСВ & PR & PPS & PDC & PRP & PRProg. & PL & PRD & PAN & Total \\
\hline Rio de Janeiro & 45,5 & 29,2 & 10,1 & 12,2 & & 0,1 & & 2,8 & & & & 0,1 & 100,0 \\
\hline Distrito Federal & 16,7 & 23,3 & 27,1 & 20,2 & 4,7 & 1,0 & 2,0 & 1,6 & 0,7 & & 2,3 & 0,4 & 100,0 \\
\hline$\underline{\text { São Paulo }}$ & 36,0 & 21,5 & 17,9 & 14,2 & & 1,9 & 4,8 & & 3,2 & & & 0,4 & 100,0 \\
\hline$\underline{\text { SUDESTE }}$ & 38,2 & 22,7 & 14,7 & 11,0 & 6,4 & 1,0 & 2,3 & 1,0 & 1,4 & & 0,9 & 0,5 & 100,0 \\
\hline Paraná & 45,3 & 24,7 & 17,7 & 3,5 & & & & 5,8 & 3,0 & & & & 100,0 \\
\hline Rio Grande do Sul & 65,0 & 9,8 & 6,7 & 6,5 & & & & 3,5 & & 8,6 & & & 100,0 \\
\hline Santa Catarina & 54,0 & 33,9 & 6,8 & 1,0 & & & & 4,3 & & & & & 100,0 \\
\hline$\underline{\text { SUL }}$ & 59,0 & 17,6 & 8,8 & 4,8 & & & & 4,1 & 0,6 & 5,2 & & & 100,0 \\
\hline Goiás & 50,1 & 41,2 & 0,0 & 8,7 & & & & & & & & & 100,0 \\
\hline Mato Grosso & 47,0 & 45,9 & 0,0 & 7,0 & & & & & & & & & 100,0 \\
\hline CENTRO-OESTE & 49,0 & 42,9 & 0,0 & 8,1 & & & & & & & & & 100,0 \\
\hline Total & 42,4 & 26,8 & 10,2 & 8,7 & 3,7 & 1,8 & 1,7 & 1,6 & 1,2 & 1,0 & 0,6 & 0,3 & 100,0 \\
\hline
\end{tabular}

Fonte: Os dados desta tabela e das seguintes foram elaborados a partir das "Fontes Primárias e Perfis Biográficos" apresentados nas referências bibliográficas. 
Tabela 2

Câmara dos Deputados: \% de Votos Obtidos por Partido e Estado

Eleições de 1950

\begin{tabular}{|c|c|c|c|c|c|c|c|c|c|c|c|c|c|c|c|}
\hline Estados & PSD & UDN & РТВ & PSP & PR & PTN & PST & PL & PRP & PDC & PRT & PSB & POT & PRB & Total \\
\hline Território do Guaporé/Rondônia & & & 51,5 & 48,5 & & & & & & & & & & & 100,0 \\
\hline Acre & 55,8 & 3,1 & 40,5 & & & & & & 0,6 & & & & & & 100,0 \\
\hline Amazonas & 38,8 & 22,4 & 12,4 & 5,0 & & & & & 3,3 & 17,3 & 0,7 & & & & 100,0 \\
\hline Território do Rio Branco/Roraima & 3,2 & & & 56,4 & & & 40,5 & & & & & & & & 100,0 \\
\hline Pará & 51,7 & 26,5 & 3,7 & 17,9 & & & & & 0,3 & & & & & & 100,0 \\
\hline Amapá & 86,9 & & 13,1 & & & & & & & & & & & & 100,0 \\
\hline NORTE & 49,4 & 23,7 & 7,3 & 15,8 & & & 0,4 & & 0,7 & 2,5 & 0,1 & & & & 100,0 \\
\hline Maranhão & 6,1 & 7,5 & 10,5 & 14,8 & 3,3 & & 56,8 & & & & 1,0 & & & & 100,0 \\
\hline Piauí & 48,4 & 51,6 & & & & & & & & & & & & & 100,0 \\
\hline Ceará & 44,9 & 44,0 & 1,3 & 9,8 & & & & & & & & 0,0 & & & 100,0 \\
\hline Rio Grande do Norte & 33,2 & 21,5 & 1,2 & 38,7 & 5,5 & & & & & & & & & & 100,0 \\
\hline Paraíba & 32,6 & 45,1 & & & & & & 22,4 & & & & & & & 100,0 \\
\hline Pernambuco & 49,8 & 22,1 & 4,5 & 1,4 & & & 5,4 & 6,8 & & 5,9 & 4,2 & & & & 100,0 \\
\hline Alagoas & 20,7 & 36,2 & & 1,2 & & & 41,5 & & 0,3 & & & & & & 100,0 \\
\hline Sergipe & 29,1 & 26,4 & 19,3 & & 21,2 & & & & & & & 4,1 & & & 100,0 \\
\hline Bahia & 41,1 & 32,7 & 17,9 & & 8,3 & & & & & & & & & & 100,0 \\
\hline NORDESTE & 38,6 & 32,9 & 6,6 & 7,4 & 3,5 & & 6,1 & 3,1 & 0,0 & 0,9 & 0,7 & 0,2 & & & 100,0 \\
\hline
\end{tabular}


Tabela 2

Câmara dos Deputados: \% de Votos Obtidos por Partido e Estado

Eleições de 1950

(continuação)

\begin{tabular}{|c|c|c|c|c|c|c|c|c|c|c|c|c|c|c|c|}
\hline Estados & PSD & UDN & РТВ & PSP & PR & PTN & PST & PL & PRP & PDC & PRT & PSB & POT & PRB & Total \\
\hline Espírito Santo & 47,6 & 22,2 & 12,8 & 7,3 & & & & & 10,1 & & & & & & 100,0 \\
\hline Minas Gerais & 39,0 & 29,6 & 13,1 & 2,2 & 11,3 & 2,2 & 0,8 & & 1,8 & & & & 0,1 & & 100,0 \\
\hline Rio de Janeiro & 35,8 & 25,2 & 26,6 & 6,8 & 1,8 & 2,4 & 0,3 & & & & 0,3 & & & 0,8 & 100,0 \\
\hline São Paulo & 15,3 & 13,2 & 20,8 & 29,3 & 2,3 & 12,3 & 0,8 & & & 2,7 & 1,5 & 1,8 & & & 100,0 \\
\hline Distrito Federal & 14,1 & 17,9 & 39,7 & 7,2 & 2,3 & 1,2 & 1,5 & 0,2 & & 3,7 & 6,6 & 2,1 & 3,3 & 0,2 & 100,0 \\
\hline SUDESTE & 26,4 & 21,0 & 21,5 & 13,6 & 5,2 & 5,7 & 0,8 & 0,0 & 0,9 & 1,5 & 1,6 & 1,0 & 0,5 & 0,1 & 100,0 \\
\hline Paraná & 41,1 & 21,4 & 28,6 & & 8,9 & & & & & & & 0,0 & & & 100,0 \\
\hline Rio Grande do Sul & 32,7 & 6,7 & 43,0 & 1,6 & 1,0 & & & 7,9 & 7,1 & & & & & & 100,0 \\
\hline Santa Catarina & 44,1 & 41,9 & 13,9 & & & & & & & & & & & & 100,0 \\
\hline SUL & 36,8 & 17,3 & 33,8 & 1,0 & 2,3 & & & 4,6 & 4,2 & & & 0,0 & & & 100,0 \\
\hline Goiás & 49,8 & 29,1 & 12,5 & 8,7 & & & & & & & & & & & 100,0 \\
\hline Mato Grosso & 37,1 & 41,4 & 19,1 & 1,0 & 1,3 & & & & & & & & & & 100,0 \\
\hline CENTRO-OESTE & 44,8 & 34,0 & 15,1 & 5,6 & 0,5 & & & & & & & & & & 100,0 \\
\hline Total & 32,8 & 24,3 & 18,5 & 9,7 & 4,0 & 2,8 & 2,2 & 1,7 & 1,1 & 1,1 & 1,0 & 0,5 & 0,3 & 0,1 & 100,0 \\
\hline
\end{tabular}

Fonte: Idem. 
Tabela 3

Câmara dos Deputados: \% de Votos Obtidos por Partido e Estado

Eleições de 1954

\begin{tabular}{|c|c|c|c|c|c|c|c|c|c|c|c|c|c|}
\hline Estados & PSD & UDN & РТВ & PSP & PR & PL & PTN & PSB & PDC & PRP & PRT & PST & Total \\
\hline Território do Guaporé/Rondônia & & & 46,9 & 53,1 & & & & & & & & & 100,0 \\
\hline Acre & 56,6 & & 43,4 & & & & & & & & & & 100,0 \\
\hline Amazonas & 19,9 & 12,4 & 54,6 & 13,2 & & & & & & & & & 100,0 \\
\hline Território do Rio Branco/Roraima & 27,5 & & 11,7 & & & & 60,8 & & & & & & 100,0 \\
\hline Pará & 42,4 & 10,7 & 12,5 & 28,6 & 4,5 & & 0,1 & 1,2 & & & & & 100,0 \\
\hline Amapá & 85,5 & & 14,5 & & & & & & & & & & 100,0 \\
\hline NORTE & 37,4 & 9,9 & 24,5 & 23,5 & 3,0 & & 0,9 & 0,8 & & & & & 100,0 \\
\hline Maranhão & 72,6 & 1,4 & & 20,2 & 1,6 & & & & 4,2 & & & & 100,0 \\
\hline Piauí & 47,7 & 33,4 & 12,0 & 6,9 & & & & & & & & & 100,0 \\
\hline Ceará & 32,9 & 34,9 & 8,7 & 19,2 & 4,3 & & & 0,0 & & & & & 100,0 \\
\hline Rio Grande do Norte & 38,0 & 35,3 & 2,0 & 24,6 & & & & & & & & & 100,0 \\
\hline Paraíba & 34,9 & 40,1 & 7,8 & & & 17,2 & & & & & & & 100,0 \\
\hline Pernambuco & 43,3 & 22,7 & 14,7 & 9,8 & & 3,9 & & & 5,5 & & & & 100,0 \\
\hline Alagoas & 14,1 & 54,9 & 21,8 & & & & & 6,7 & & & & 2,5 & 100,0 \\
\hline Sergipe & 33,6 & 39,8 & 16,6 & & 9,9 & & & & & & & & 100,0 \\
\hline Bahia & 27,1 & 22,9 & 15,8 & 0,2 & 19,4 & 10,6 & & & 1,5 & 2,7 & & & 100,0 \\
\hline NORDESTE & 36,7 & 29,3 & 11,1 & 9,3 & 6,3 & 4,8 & & 0,3 & 1,4 & 0,7 & & 0,1 & 100,0 \\
\hline
\end{tabular}


Tabela 3

Câmara dos Deputados: \% de Votos Obtidos por Partido e Estado

Eleições de 1954

(continuação)

\begin{tabular}{|c|c|c|c|c|c|c|c|c|c|c|c|c|c|}
\hline Estados & PSD & UDN & РТВ & PSP & PR & PL & PTN & PSB & PDC & PRP & PRT & PST & Total \\
\hline Espírito Santo & 43,9 & 7,5 & 26,4 & 7,5 & 4,4 & & & & & 10,3 & & & 100,0 \\
\hline Minas Gerais & 44,9 & 25,1 & 12,5 & 4,5 & 13,0 & & & & & & & & 100,0 \\
\hline Rio de Janeiro & 33,2 & 28,7 & 24,2 & 4,8 & & 4,0 & & 2,5 & 2,5 & & 0,1 & & 100,0 \\
\hline São Paulo & 23,5 & 8,8 & 17,6 & 25,1 & 4,4 & & 10,9 & 4,8 & 2,6 & & 0,5 & 1,7 & 100,0 \\
\hline Distrito Federal & 10,6 & 31,1 & 30,6 & 11,6 & 0,8 & 0,6 & & 3,4 & 2,5 & & 8,7 & & 100,0 \\
\hline SUDESTE & 30,3 & 19,5 & 18,9 & 13,7 & 6,1 & 0,5 & 4,3 & 2,6 & 1,7 & 0,3 & 1,5 & 0,7 & 100,0 \\
\hline Paraná & 28,4 & 19,8 & 27,9 & 10,4 & 13,5 & & & & & & & & 100,0 \\
\hline Rio Grande do Sul & 28,8 & 4,9 & 42,1 & 1,3 & & 11,7 & & 2,0 & 0,6 & 8,7 & & & 100,0 \\
\hline Santa Catarina & 38,1 & 42,5 & 6,3 & 2,9 & & & & & 10,2 & & & & 100,0 \\
\hline SUL & 30,6 & 16,2 & 31,3 & 4,0 & 3,5 & 6,3 & & 1,1 & 2,3 & 4,7 & & & 100,0 \\
\hline Goiás & 45,5 & 31,0 & 5,5 & 18,0 & & & & & & & & & 100,0 \\
\hline Mato Grosso & 31,8 & 49,3 & 9,7 & 9,2 & & & & & & & & & 100,0 \\
\hline CENTRO-OESTE & 40,3 & 37,9 & 7,1 & 14,7 & & & & & & & & & 100,0 \\
\hline Total & 32,6 & 21,9 & 18,7 & 11,2 & 5,5 & 2,6 & 2,2 & 1,6 & 1,6 & 1,1 & 0,7 & 0,4 & 100,0 \\
\hline
\end{tabular}

Fonte: Idem. 
Tabela 4

Câmara dos Deputados: \% de Votos Obtidos por Partido e Estado

Eleições de 1958

\begin{tabular}{|c|c|c|c|c|c|c|c|c|c|c|c|c|c|}
\hline Estados & PSD & UDN & РТВ & PSP & PR & PDC & PTN & PSB & PRP & PL & PST & PRT & Total \\
\hline Território do Guaporé/Rondônia & & & 53,2 & 46,1 & & & & & & 0,6 & & & 100,0 \\
\hline Acre & 46,1 & 10,6 & 41,0 & 2,3 & & & & & & & & & 100,0 \\
\hline Amazonas & 22,7 & 7,8 & 44,5 & 7,5 & & & & & & & 17,5 & & 100,0 \\
\hline Território do Rio Branco/Roraima & 58,3 & & & & & & 41,7 & & & & & & 100,0 \\
\hline Pará & 46,1 & 28,9 & 11,1 & 13,9 & & & & & & & & & 100,0 \\
\hline Amapá & 55,6 & & 44,4 & & & & & & & & & & 100,0 \\
\hline NORTE & 40,4 & 21,6 & 21,3 & 12,1 & & & 0,8 & & & 0,0 & 3,8 & & 100,0 \\
\hline Maranhão & 63,4 & 15,8 & 0,0 & 20,8 & & & & & & & & & 100,0 \\
\hline Piauí & 36,6 & 31,1 & 23,0 & 9,3 & & & & & & & & & 100,0 \\
\hline Ceará & 33,9 & 40,2 & 13,2 & 6,5 & 3,0 & & & & & & & 3,2 & 100,0 \\
\hline Rio Grande do Norte & 51,8 & 48,2 & & & & & & & & & & & 100,0 \\
\hline Paraíba & 47,0 & 32,8 & & 20,2 & & & & & & & 0,0 & & 100,0 \\
\hline Pernambuco & 51,3 & 11,6 & 26,5 & & & 2,6 & & 2,9 & & 5,0 & & & 100,0 \\
\hline Alagoas & 21,1 & 30,8 & 18,4 & 20,0 & & & & 9,7 & & & & & 100,0 \\
\hline Sergipe & 24,7 & 52,8 & 12,1 & & 10,3 & & & & & & & & 100,0 \\
\hline Bahia & 35,1 & 32,6 & 8,5 & & 19,4 & 4,4 & & & & & & & 100,0 \\
\hline NORDESTE & 41,1 & 30,8 & 12,1 & 5,7 & 6,3 & 1,7 & & 0,9 & & 0,9 & 0,0 & 0,6 & 100,0 \\
\hline
\end{tabular}


Tabela 4

Câmara dos Deputados: \% de Votos Obtidos por Partido e Estado

Eleições de 1958

\begin{tabular}{|c|c|c|c|c|c|c|c|c|c|c|c|c|c|}
\hline Estados & PSD & UDN & РТВ & PSP & PR & PDC & PTN & PSB & PRP & PL & PST & PRT & Total \\
\hline Espírito Santo & 46,4 & 16,8 & 28,5 & & & & & & 8,3 & & & & 100,0 \\
\hline Minas Gerais & 44,6 & 20,7 & 12,8 & & 22,0 & & & & & & & & 100,0 \\
\hline Rio de Janeiro & 38,1 & 24,8 & 24,8 & 9,3 & & & & 3,0 & & & & & 100,0 \\
\hline São Paulo & 23,6 & 10,6 & 11,7 & 10,8 & 2,9 & 8,9 & 12,6 & 8,8 & 2,8 & & 4,4 & 2,9 & 100,0 \\
\hline$\underline{\text { Distrito Federal }}$ & 4,6 & 35,1 & 31,7 & 23,0 & & 0,8 & & 2,4 & & 1,1 & 1,3 & 0,0 & 100,0 \\
\hline$\underline{\text { SUDESTE }}$ & 29,8 & 19,1 & 17,0 & 8,7 & 8,1 & 3,6 & 5,0 & 4,2 & 1,4 & 0,2 & 1,9 & 1,1 & 100,0 \\
\hline Paraná & 26,7 & 6,9 & 41,3 & & 3,2 & 11,5 & & & 10,4 & & & & 100,0 \\
\hline Rio Grande do Sul & 25,1 & 4,3 & 52,5 & 0,1 & & 1,8 & & & 5,6 & 10,5 & & & 100,0 \\
\hline$\underline{\text { Santa Catarina }}$ & 45,9 & 42,4 & 11,7 & & & & & & & & & & 100,0 \\
\hline SUL & 30,0 & 13,1 & 40,9 & 0,1 & 0,8 & 3,9 & & & 5,6 & 5,6 & & & 100,0 \\
\hline Goiás & 58,3 & 14,9 & 14,7 & 12,1 & & & & & & & & & 100,0 \\
\hline Mato Grosso & 33,4 & 51,0 & 15,6 & & & & & & & & & & 100,0 \\
\hline CENTRO-OESTE & 50,3 & 26,6 & 15,0 & 8,2 & & & & & & & & & 100,0 \\
\hline Total & 33,6 & 21,1 & 20,5 & 6,3 & 5,7 & 3,0 & 2,5 & 2,3 & 1,8 & 1,4 & 1,1 & 0,7 & 100,0 \\
\hline
\end{tabular}

Fonte: Idem. 
Tabela 5

Câmara dos Deputados: \% de Votos Obtidos por Partido e Estado

Eleições de 1962

\begin{tabular}{|c|c|c|c|c|c|c|c|c|c|c|c|c|c|c|}
\hline Estados & PSD & РТВ & UDN & PDC & PSP & PTN & PR & PST & PRP & PL & MTR & PRT & PSB & Total \\
\hline Território do Guaporé/Rondônia & 23,6 & 23,6 & & & 52,7 & & & & & & & & & 100,0 \\
\hline Acre & 49,9 & 49,0 & & & & & & & & & & & 1,2 & 100,0 \\
\hline Amazonas & 33,6 & 38,0 & & & & & & & & 28,4 & & & & 100,0 \\
\hline Território do Rio Branco/Roraima & 12,4 & 62,9 & 12,4 & & & & & & & & & & 12,4 & 100,0 \\
\hline Pará & 44,0 & 20,6 & 18,3 & & 17,1 & & & & & & & & & 100,0 \\
\hline Amapá & 19,0 & 19,0 & & & 62,0 & & & & & & & & & 100,0 \\
\hline NORTE & 39,6 & 27,2 & 11,3 & & 13,8 & & & & & 7,8 & & & 0,2 & 100,0 \\
\hline Maranhão & 70,3 & & 10,7 & & 18,9 & & & & & & & & & 100,0 \\
\hline Piauí & 34,5 & 36,0 & 21,3 & 6,7 & & & & & & & 1,5 & & & 100,0 \\
\hline Ceará & 34,1 & 29,1 & 32,0 & & & 4,8 & & & & & & & & 100,0 \\
\hline Rio Grande do Norte & 41,4 & & 33,6 & 24,7 & & & & & & & & & 0,3 & 100,0 \\
\hline Paraíba & 37,6 & 18,2 & 39,4 & & & & & & & & & & 4,8 & 100,0 \\
\hline Pernambuco & 15,4 & 40,8 & 27,7 & 6,6 & & & & 5,9 & & & & & 3,5 & 100,0 \\
\hline Alagoas & 17,8 & 20,9 & 47,6 & & 13,6 & & & 0,0 & & & & & & 100,0 \\
\hline Sergipe & 26,2 & 11,3 & 49,4 & & & & 13,1 & & & & & & & 100,0 \\
\hline Bahia & 32,3 & 24,8 & 32,2 & 1,4 & & 1,5 & 3,7 & 0,7 & 1,2 & & & & 2,2 & 100,0 \\
\hline NORDESTE & 34,3 & 23,4 & 30,5 & 3,7 & 2,5 & 1,2 & 1,3 & 1,1 & 0,3 & & 0,1 & & 1,6 & 100,0 \\
\hline
\end{tabular}


Tabela 5

Câmara dos Deputados: \% de Votos Obtidos por Partido e Estado

Eleições de 1962

\begin{tabular}{|c|c|c|c|c|c|c|c|c|c|c|c|c|c|c|}
\hline Estados & PSD & РТВ & UDN & PDC & PSP & PTN & PR & PST & PRP & PL & MTR & PRT & PSB & Total \\
\hline Espírito Santo & 32,2 & 16,6 & 20,5 & & 3,3 & 12,9 & & & 14,6 & & & & & 100,0 \\
\hline Minas Gerais & 45,5 & 9,5 & 33,5 & & 1,0 & & 10,3 & & & & 0,1 & & & 100,0 \\
\hline Rio de Janeiro & 27,0 & 36,3 & 16,4 & & 9,1 & & & 8,5 & & & & & 2,6 & 100,0 \\
\hline São Paulo & 16,6 & 11,0 & 9,7 & 15,3 & 15,8 & 12,9 & 5,0 & 3,9 & 3,5 & & 2,1 & 4,2 & 0,0 & 100,0 \\
\hline$\underline{\text { Distrito Federal }}$ & 8,5 & 50,4 & 31,3 & 6,5 & & & & 2,6 & & & & & 0,7 & 100,0 \\
\hline SUDESTE & 26,2 & 20,1 & 21,6 & 6,7 & 7,5 & 5,3 & 5,0 & 3,0 & 1,9 & & 0,8 & 1,6 & 0,4 & 100,0 \\
\hline Paraná & 26,8 & 38,6 & 18,4 & 14,6 & & & & & & & & & 1,5 & 100,0 \\
\hline Rio Grande do Sul & 25,1 & 48,6 & 2,9 & 4,6 & & & & & 3,4 & 9,6 & 5,9 & & & 100,0 \\
\hline$\underline{\text { Santa Catarina }}$ & 44,1 & 13,8 & 42,1 & & & & & 0,0 & & & & & & 100,0 \\
\hline SUL & 29,7 & 38,3 & 15,7 & 6,4 & & & & 0,0 & 1,7 & 4,8 & 2,9 & & 0,4 & 100,0 \\
\hline Goiás & 55,5 & 18,3 & 12,9 & 2,5 & 10,9 & & & & & & & & & 100,0 \\
\hline Mato Grosso & 31,8 & 19,0 & 49,2 & & & & & & & & & & & 100,0 \\
\hline CENTRO-OESTE & 46,8 & 18,5 & 26,3 & 1,6 & 6,9 & & & & & & & & & 100,0 \\
\hline Total & 30,1 & 24,8 & 22,6 & 5,5 & 4,9 & 2,8 & 2,7 & 1,7 & 1,3 & 1,2 & 1,0 & 0,7 & 0,7 & 100,0 \\
\hline
\end{tabular}

Fonte: Idem. 
ANEXO 2

Tabela 1

Câmara dos Deputados: Número de Cadeiras por Partido e Estado

Eleições de 1945

\begin{tabular}{|c|c|c|c|c|c|c|c|c|c|c|}
\hline Estados & PSD & UDN & РТВ & РCB & PR & PPS & PDC & PRProg. & PL & Total \\
\hline Acre & 2 & & & & & & & & & 2 \\
\hline Amazonas & 3 & 1 & 1 & & & & & & & 5 \\
\hline Pará & 6 & 2 & & & & 1 & & & & 9 \\
\hline NORTE & 11 & 3 & 1 & & & 1 & & & & 16 \\
\hline Maranhão & 6 & 2 & & & 1 & & & & & 9 \\
\hline Piauí & 3 & 4 & & & & & & & & 7 \\
\hline Ceará & 5 & 10 & & & & 2 & & & & 17 \\
\hline Rio Grande do Norte & 4 & 2 & & & & & & 1 & & 7 \\
\hline Paraíba & 3 & 7 & & & & & & & & 10 \\
\hline Pernambuco & 10 & 4 & & 3 & 1 & & 1 & & & 19 \\
\hline Alagoas & 6 & 3 & & & & & & & & 9 \\
\hline Sergipe & 2 & 2 & & & 1 & & & & & 5 \\
\hline Bahia & 9 & 12 & 1 & 1 & & 1 & & & & 24 \\
\hline NORDESTE & 48 & 46 & 1 & 4 & 3 & 3 & 1 & 1 & & 107 \\
\hline Espírito Santo & 6 & 1 & & & & & & & & 7 \\
\hline Minas Gerais & 20 & 7 & 2 & & 6 & & & & & 35 \\
\hline
\end{tabular}


Tabela 1

Câmara dos Deputados: Número de Cadeiras por Partido e Estado

Eleições de 1945

\begin{tabular}{|c|c|c|c|c|c|c|c|c|c|c|}
\hline Estados & PSD & UDN & РTB & РСВ & PR & PPS & PDC & PRProg. & PL & Total \\
\hline Rio de Janeiro & 10 & 4 & 1 & 2 & & & & & & 17 \\
\hline Distrito Federal & 2 & 3 & 9 & 3 & & & & & & 17 \\
\hline São Paulo & 16 & 7 & 6 & 4 & & & 1 & 1 & & 35 \\
\hline SUDESTE & 54 & 22 & 18 & 9 & 6 & & 1 & 1 & & 111 \\
\hline Paraná & 6 & 2 & 1 & & & & & & & 9 \\
\hline Rio Grande do Sul & 17 & 2 & 1 & 1 & & & & & 1 & 22 \\
\hline Santa Catarina & 7 & 2 & & & & & & & & 9 \\
\hline SUL & 30 & 6 & 2 & 1 & & & & & 1 & 40 \\
\hline Goiás & 5 & 2 & & & & & & & & 7 \\
\hline Mato Grosso & 3 & 2 & & & & & & & & 5 \\
\hline CENTRO-OESTE & 8 & 4 & & & & & & & & 12 \\
\hline Total & 151 & 81 & 22 & 14 & 9 & 4 & 2 & 2 & 1 & 286 \\
\hline
\end{tabular}

Fonte: Idem. 
Tabela 2

Câmara dos Deputados: Número de Cadeiras por Partido e Estado

Eleições de 1950

\begin{tabular}{|c|c|c|c|c|c|c|c|c|c|c|c|c|c|}
\hline Estados & UDN & PSD & РТВ & PSP & PR & PST & PL & PTN & PDC & PRP & PSB & PRT & Total \\
\hline Território do Guaporé/Rondônia & & & & 1 & & & & & & & & & 1 \\
\hline Acre & 1 & & 1 & & & & & & & & & & 2 \\
\hline Amazonas & 3 & 2 & 1 & & & & & & 1 & & & & 7 \\
\hline Território do Rio Branco/Roraima & & & & 1 & & & & & & & & & 1 \\
\hline Pará & 5 & 2 & & 2 & & & & & & & & & 9 \\
\hline Amapá & 1 & & & & & & & & & & & & 1 \\
\hline NORTE & 10 & 4 & 2 & 4 & & & & & 1 & & & & 21 \\
\hline Maranhão & & 1 & 1 & 2 & & 5 & & & & & & & 9 \\
\hline Piauí & 3 & 4 & & & & & & & & & & & 7 \\
\hline Ceará & 8 & 8 & & 1 & & & & & & & & & 17 \\
\hline Rio Grande do Norte & 3 & 3 & & & 1 & & & & & & & & 7 \\
\hline Paraíba & 4 & 4 & & & & & 2 & & & & & & 10 \\
\hline Pernambuco & 9 & 6 & 1 & & & & 2 & & 1 & & & & 19 \\
\hline Alagoas & 2 & 3 & & & & 4 & & & & & & & 9 \\
\hline Sergipe & 2 & 2 & 1 & & 1 & & & & & & 1 & & 7 \\
\hline Bahia & 11 & 7 & 4 & & 3 & & & & & & & & 25 \\
\hline NORDESTE & 42 & 38 & 7 & 3 & 5 & 9 & 4 & & 1 & & 1 & & 110 \\
\hline
\end{tabular}


Tabela 2

Câmara dos Deputados: Número de Cadeiras por Partido e Estado

Eleições de 1950

\begin{tabular}{|c|c|c|c|c|c|c|c|c|c|c|c|c|c|}
\hline Estados & UDN & PSD & РТВ & PSP & PR & PST & PL & PTN & PDC & PRP & PSB & PRT & Total \\
\hline Minas Gerais & 17 & 12 & 5 & & 4 & & & & & & & & 38 \\
\hline Espírito Santo & 4 & 1 & & 1 & & & & & & 1 & & & 7 \\
\hline Rio de Janeiro & 7 & 4 & 5 & 1 & & & & & & & & & 17 \\
\hline São Paulo & 7 & 6 & 9 & 13 & & & & 5 & & & & & 40 \\
\hline$\underline{\text { Distrito Federal }}$ & 3 & 4 & 8 & 1 & & & & & & & & 1 & 17 \\
\hline$\underline{\text { SUDESTE }}$ & 38 & 27 & 27 & 16 & 4 & & & 5 & & 1 & & 1 & 119 \\
\hline Paraná & 3 & 2 & 3 & & 1 & & & & & & & & 9 \\
\hline Rio Grande do Sul & 8 & 1 & 10 & & & & 2 & & & 1 & & & 22 \\
\hline$\underline{\text { Santa Catarina }}$ & 4 & 4 & 1 & & & & & & & & & & 9 \\
\hline$\underline{\text { SUL }}$ & 15 & 7 & 14 & & 1 & & 2 & & & 1 & & & 40 \\
\hline Goiás & 4 & 2 & & 1 & & & & & & & & & 7 \\
\hline Mato Grosso & 3 & 3 & 1 & & & & & & & & & & 7 \\
\hline CENTRO-OESTE & 7 & 5 & 1 & 1 & & & & & & & & & 14 \\
\hline Total & 112 & 81 & 51 & 24 & 10 & 9 & 6 & 5 & 2 & 2 & 1 & 1 & 304 \\
\hline
\end{tabular}

Fonte: Idem. 
Tabela 3

Câmara dos Deputados: Número de Cadeiras por Partido e Estado

\begin{tabular}{|c|c|c|c|c|c|c|c|c|c|c|c|c|}
\hline \multicolumn{13}{|c|}{ Eleições de 1954} \\
\hline Estados & PSD & UDN & РТВ & PSP & PR & PL & PTN & PRP & PSB & PDC & PRT & Total \\
\hline Território do Guaporé/Rondônia & 1 & & & & & & & & & & & 1 \\
\hline Acre & 1 & & 1 & & & & & & & & & 2 \\
\hline Amazonas & 3 & & 4 & & & & & & & & & 7 \\
\hline Território do Rio Branco/Roraima & & & & & & & 1 & & & & & 1 \\
\hline Pará & 6 & & & 3 & & & & & & & & 9 \\
\hline Amapá & 1 & & & & & & & & & & & 1 \\
\hline NORTE & 12 & & 5 & 3 & & & 1 & & & & & 21 \\
\hline Maranhão & 8 & & & 2 & & & & & & & & 10 \\
\hline Piauí & 3 & 2 & 1 & 1 & & & & & & & & 7 \\
\hline Ceará & 5 & 7 & 1 & 3 & 1 & & & & 1 & & & 18 \\
\hline Rio Grande do Norte & 3 & 2 & 2 & & & & & & & & & 7 \\
\hline Paraíba & 3 & 5 & & & & 3 & & & & & & 11 \\
\hline Pernambuco & 12 & 4 & 3 & 1 & & 1 & & & & 1 & & 22 \\
\hline Alagoas & 1 & 5 & 2 & & & & & & 1 & & & 9 \\
\hline Sergipe & 2 & 3 & 1 & & 1 & & & & & & & 7 \\
\hline Bahia & 7 & 6 & 4 & & 6 & 3 & & 1 & & & & 27 \\
\hline NORDESTE & 44 & 34 & 14 & 7 & 8 & 7 & & 1 & 2 & 1 & & 118 \\
\hline
\end{tabular}


Tabela 3

Câmara dos Deputados: Número de Cadeiras por Partido e Estado

Eleições de 1954

\begin{tabular}{|c|c|c|c|c|c|c|c|c|c|c|c|c|}
\hline Estados & PSD & UDN & РТВ & PSP & PR & PL & PTN & PRP & PSB & PDC & PRT & Total \\
\hline Espírito Santo & 4 & & 2 & & & & & 1 & & & & 7 \\
\hline Minas Gerais & 18 & 10 & 5 & 1 & 5 & & & & & & & 39 \\
\hline Rio de Janeiro & 6 & 6 & 5 & & & & & & & & & 17 \\
\hline São Paulo & 11 & 4 & 8 & 11 & 2 & & 5 & & 2 & 1 & & 44 \\
\hline Distrito Federal & 2 & 5 & 6 & 2 & 1 & & & & & & 1 & 17 \\
\hline SUDESTE & 41 & 25 & 26 & 14 & 8 & & 5 & 1 & 2 & 1 & 1 & 124 \\
\hline Paraná & 4 & 3 & 4 & 1 & 2 & & & & & & & 14 \\
\hline Rio Grande do Sul & 7 & 1 & 11 & & & 3 & & 2 & & & & 24 \\
\hline Santa Catarina & 5 & 5 & & & & & & & & & & 10 \\
\hline$\underline{\text { SUL }}$ & 16 & 9 & 15 & 1 & 2 & 3 & & 2 & & & & 48 \\
\hline Goiás & 4 & 2 & & 2 & & & & & & & & 8 \\
\hline Mato Grosso & 2 & 4 & 1 & & & & & & & & & 7 \\
\hline CENTRO-OESTE & 6 & 6 & 1 & 2 & & & & & & & & 15 \\
\hline Total & 119 & 74 & 61 & 27 & 18 & 10 & 6 & 4 & 4 & 2 & 1 & 326 \\
\hline
\end{tabular}

Fonte: Idem. 
Tabela 4

Câmara dos Deputados: Número de Cadeiras por Partido e Estado

Eleições de 1958

\begin{tabular}{|c|c|c|c|c|c|c|c|c|c|c|c|c|c|}
\hline Estados & PSD & UDN & РТВ & PSP & PR & PSB & PDC & PTN & PL & PRP & PRT & PST & Total \\
\hline Território do Guaporé/Rondônia & & & 1 & & & & & & & & & & 1 \\
\hline Acre & 1 & & 1 & & & & & & & & & & 2 \\
\hline Amazonas & 1 & 1 & 2 & 1 & & & & & & & & 1 & 6 \\
\hline Território do Rio Branco/Roraima & 1 & & & & & & & & & & & & 1 \\
\hline Pará & 4 & 3 & & 2 & & & & & & & & & 9 \\
\hline Amapá & 1 & & & & & & & & & & & & 1 \\
\hline NORTE & 8 & 4 & 4 & 3 & & & & & & & & 1 & 20 \\
\hline Maranhão & 6 & 1 & & 3 & & & & & & & & & 10 \\
\hline Piauí & 2 & 2 & 2 & 1 & & & & & & & & & 7 \\
\hline Ceará & 6 & 6 & 2 & 2 & 1 & & & & & & 1 & & 18 \\
\hline Rio Grande do Norte & 4 & 3 & & & & & & & & & & & 7 \\
\hline Paraíba & 5 & 4 & & 2 & & & & & & & & & 11 \\
\hline Pernambuco & 11 & 3 & 6 & & & 1 & 1 & & 1 & & & & 23 \\
\hline Alagoas & 2 & 2 & 2 & 2 & & 1 & & & & & & & 9 \\
\hline Sergipe & 2 & 4 & & & 1 & & & & & & & & 7 \\
\hline Bahia & 10 & 9 & 2 & & 5 & & 1 & & & & & & 27 \\
\hline NORDESTE & 48 & 34 & 14 & 10 & 7 & 2 & 2 & & 1 & & 1 & & 119 \\
\hline
\end{tabular}


Tabela 4

Câmara dos Deputados: Número de Cadeiras por Partido e Estado

Eleições de 1958

\begin{tabular}{|c|c|c|c|c|c|c|c|c|c|c|c|c|c|}
\hline Estados & PSD & UDN & РТВ & PSP & PR & PSB & PDC & PTN & PL & PRP & PRT & PST & Total \\
\hline Espírito Santo & 3 & 1 & 2 & & & & & & & 1 & & & 7 \\
\hline Minas Gerais & 18 & 8 & 5 & & 8 & & & & & & & & 39 \\
\hline Rio de Janeiro & 6 & 4 & 5 & 1 & & 1 & & & & & & & 17 \\
\hline São Paulo & 11 & 4 & 5 & 6 & 1 & 5 & 4 & 6 & & & 1 & 1 & 44 \\
\hline Distrito Federal & 1 & 6 & 5 & 4 & & 1 & & & & & & & 17 \\
\hline SUDESTE & 39 & 23 & 22 & 11 & 9 & 7 & 4 & 6 & & 1 & 1 & 1 & 124 \\
\hline Paraná & 4 & 1 & 6 & & 1 & & 1 & & & 1 & & & 14 \\
\hline Rio Grande do Sul & 7 & & 14 & & & & & & 2 & 1 & & & 24 \\
\hline$\underline{\text { Santa Catarina }}$ & 5 & 4 & 1 & & & & & & & & & & 10 \\
\hline SUL & 16 & 5 & 21 & & 1 & & 1 & & 2 & 2 & & & 48 \\
\hline Goiás & 5 & 1 & 1 & 1 & & & & & & & & & 8 \\
\hline Mato Grosso & 3 & 3 & 1 & & & & & & & & & & 7 \\
\hline CENTRO-OESTE & 8 & 4 & 2 & 1 & & & & & & & & & 15 \\
\hline Total & 119 & 70 & 63 & 25 & 17 & 9 & 7 & 6 & 3 & 3 & 2 & 2 & 326 \\
\hline
\end{tabular}

Fonte: Idem. 
Tabela 5

Câmara dos Deputados: Número de Cadeiras por Partido e Estado Eleições de 1962

\begin{tabular}{|c|c|c|c|c|c|c|c|c|c|c|c|c|c|c|}
\hline Estados & PSD & РТВ & UDN & PSP & PDC & PTN & PR & PST & PL & PSB & PRP & PRT & MTR & Total \\
\hline Território do Guaporé/Rondônia & & & & 1 & & & & & & & & & & 1 \\
\hline Acre & 4 & 3 & & & & & & & & & & & & 7 \\
\hline Amazonas & 2 & 3 & & & & & & & 2 & & & & & 7 \\
\hline Território do Rio Branco/Roraima & & 1 & & & & & & & & & & & & 1 \\
\hline Pará & 4 & 2 & 2 & 2 & & & & & & & & & & 10 \\
\hline Amapá & 1 & & & & & & & & & & & & & 1 \\
\hline NORTE & 11 & 9 & 2 & 3 & & & & & 2 & & & & & 27 \\
\hline Maranhão & 11 & & 2 & 3 & & & & & & & & & & 16 \\
\hline Piauí & 3 & 3 & 2 & & & & & & & & & & & 8 \\
\hline Ceará & 7 & 5 & 7 & & & 1 & & 1 & & & & & & 21 \\
\hline Rio Grande do Norte & 3 & & 2 & & 2 & & & & & & & & & 7 \\
\hline Paraíba & 5 & 2 & 6 & & & & & & & & & & & 13 \\
\hline Pernambuco & 5 & 9 & 7 & & 1 & & & 1 & & 1 & & & & 24 \\
\hline Alagoas & 1 & 2 & 5 & 1 & & & & & & & & & & 9 \\
\hline Sergipe & 2 & 2 & 3 & & & & & & & & & & & 7 \\
\hline Bahia & 10 & 9 & 9 & & & 1 & 1 & & & 1 & & & & 31 \\
\hline NORDESTE & 47 & 32 & 43 & 4 & 3 & 2 & 1 & 2 & & 2 & & & & 136 \\
\hline
\end{tabular}


Tabela 5

Câmara dos Deputados: Número de Cadeiras por Partido e Estado

Eleições de 1962

\begin{tabular}{|c|c|c|c|c|c|c|c|c|c|c|c|c|c|c|}
\hline Estados & PSD & РТВ & UDN & PSP & PDC & PTN & PR & PST & PL & PSB & PRP & PRT & MTR & Total \\
\hline Espírito Santo & 2 & 2 & 1 & & & 2 & & & & & 1 & & & 8 \\
\hline Minas Gerais & 21 & 6 & 16 & 1 & & & 4 & & & & & & & 48 \\
\hline Rio de Janeiro & 5 & 8 & 3 & 2 & & & & 2 & & 1 & & & & 21 \\
\hline São Paulo & 8 & 9 & 7 & 9 & 9 & 7 & 2 & 2 & & & 1 & 3 & 2 & 59 \\
\hline Distrito Federal & 2 & 10 & 6 & & 1 & & & 1 & & 1 & & & & 21 \\
\hline SUDESTE & 38 & 35 & 33 & 12 & 10 & 9 & 6 & 5 & & 2 & 2 & 3 & 2 & 157 \\
\hline Paraná & 6 & 10 & 5 & & 4 & & & & & & & & & 25 \\
\hline Rio Grande do Sul & 7 & 14 & 1 & & 2 & & & & 3 & & 1 & & 1 & 29 \\
\hline Santa Catarina & 6 & 2 & 6 & & & & & & & & & & & 14 \\
\hline SUL & 19 & 26 & 12 & & 6 & & & & 3 & & 1 & & 1 & 68 \\
\hline Goiás & 7 & 2 & 2 & 2 & & & & & & & & & & 13 \\
\hline Mato Grosso & 3 & 1 & 4 & & & & & & & & & & & 8 \\
\hline CENTRO-OESTE & 10 & 3 & 6 & 2 & & & & & & & & & & 21 \\
\hline Total & 125 & 105 & 96 & 21 & 19 & 11 & 7 & 7 & 5 & 4 & 3 & 3 & 3 & 409 \\
\hline
\end{tabular}

Fonte: Idem. 


\section{ANEXO 3}

Volatilidade Parlamentar Total. Cadeiras da Câmara dos Deputados (1945-62)

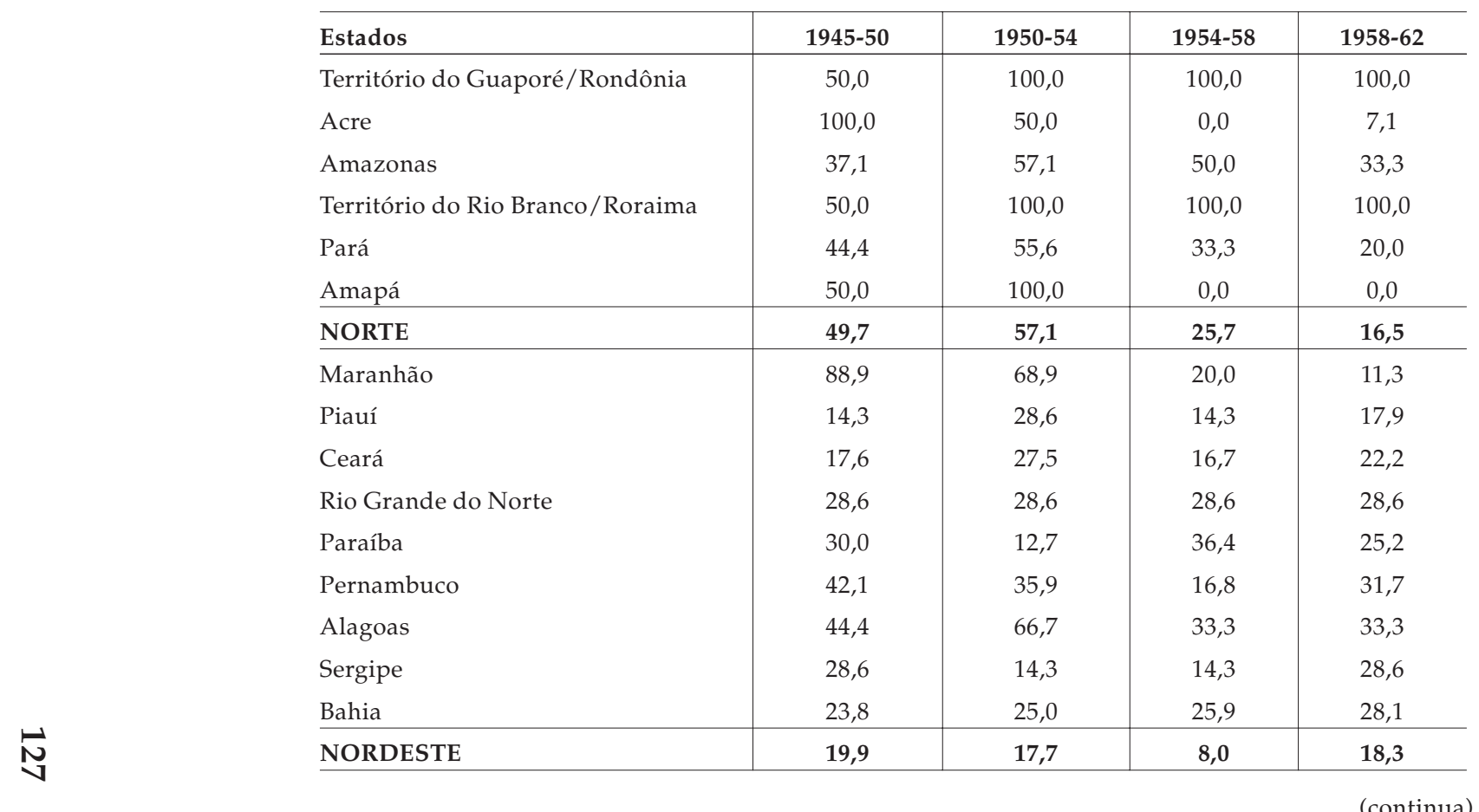


Volatilidade Parlamentar Total. Cadeiras da Câmara dos Deputados

\begin{tabular}{l|c|c|c|c}
\hline Estados & $\mathbf{1 9 4 5 - 5 0}$ & $\mathbf{1 9 5 0 - 5 4}$ & $\mathbf{1 9 5 4 - 5 8}$ & $\mathbf{1 9 5 8 - 6 2}$ \\
\hline Espírito Santo & 54,1 & 55,3 & 14,3 & 25,0 \\
Minas Gerais & 65,7 & 57,5 & 7,7 & 14,9 \\
Rio de Janeiro & 47,1 & 11,8 & 11,8 & 21,8 \\
São Paulo & 48,2 & 21,4 & 20,5 & 24,6 \\
Distrito Federal & 38,8 & 23,5 & 23,5 & 31,4 \\
\hline SUDESTE & $\mathbf{3 7 , 0}$ & $\mathbf{1 5 , 9}$ & $\mathbf{9 , 7}$ & $\mathbf{1 6 , 3}$ \\
\hline Paraná & 44,4 & 16,7 & 28,6 & 21,7 \\
Rio Grande do Sul & 77,3 & 32,2 & 12,5 & 15,8 \\
Santa Catarina & 33,3 & 11,1 & 10,0 & 7,1 \\
\hline SUL & $\mathbf{6 0 , 0}$ & $\mathbf{2 2 , 5}$ & $\mathbf{1 4 , 6}$ & $\mathbf{1 5 , 7}$ \\
\hline Goiás & 42,9 & 32,1 & 25,0 & 8,7 \\
Mato Grosso & 17,1 & 14,3 & 14,3 & 7,1 \\
\hline CENTRO-OESTE & $\mathbf{3 1 , 0}$ & $\mathbf{1 0 , 5}$ & $\mathbf{2 0 , 0}$ & $\mathbf{5 , 7}$ \\
\hline Total & $\mathbf{3 1 , 1}$ & $\mathbf{1 7 , 2}$ & $\mathbf{4 , 6}$ & $\mathbf{1 3 , 9}$ \\
\hline
\end{tabular}

Fonte: Idem. 


\begin{abstract}
Political Parties in the Republic of 1946: Old Theses, New Data

This article proposes a new way of organizing Brazilian electoral data from 1945 to 1962 and discusses some classic interpretations of the country's political party system. One obstacle to research on parties in the Republic of 1946 was the lack of complete party-by-party data. The reason is that official statistics did not distinguish data by party in the case of joint party slates for the Legislative Branch. The purpose of this study was to overcome this limitation by identifying the party affiliations of candidates in each slate. This approach allowed the partisan identification of nearly all of the votes. The second part of the article evaluates some of the classic political proposals from the same period: conservative parties were on the decline and the Brazilian Labor Party (PTB) on the rise; parties were undergoing continuous nationalization; and the party system was becoming increasingly fragmented.
\end{abstract}

Key words: parties; elections; party system

\title{
RÉSUMÉ \\ Les Partis dans la République de 1946: Thèses Anciennes, Nouvelles Données
}

Dans cet article, on propose une nouvelle façon d'exploiter les données électorales concernant la période 1945-1962 et on revient sur quelques interprétations classiques à propos du système brésilien des partis. Il manquait à la recherche sur les partis de la République de 1946 des données complètes pour chaque parti car les statistiques officielles, dans les cas d'alliances, ne faisaient pas la distinction entre les partis. On propose ici de dépasser cette limite par l'identification du parti des candidats dans chaque liste, ce qui permet d'aboutir au chiffre de voix données à chaque parti. Dans un second temps, on examine quelques propositions classiques de la période; les partis conservateurs déclinaient tandis que le PTB (Parti Travailliste du Brésil) progressait; les partis se trouvaient dans un processus continu de nationalisation; le système des partis se morcelait de plus en plus.

Mots-clé: partis; élections; système de partis 